\title{
Optimization Transmission Efficiency with Driver Intention for Automotive Continuously Variable Transmission Under Slip Mode
}

Ling Han ( $\square$ hanling@ccut.edu.cn )

Changchun University of Technology

Hui Zhang

Changchun University of Technology

Ruoyu Fang

Changchun University of Technology

Hongxiang Liu

Changchun University of Technology

Original Article

Keywords:

Posted Date: November 25th, 2020

DOI: https://doi.org/10.21203/rs.3.rs-113056/v1

License: (1) This work is licensed under a Creative Commons Attribution 4.0 International License.

Read Full License 


\section{Title page}

\section{Optimization transmission efficiency with driver intention for automotive continuously variable transmission under slip mode}

Ling Han, born in 1984, is currently an associate professor at Changchun University of Technology, China. She received her PhD degree from Jilin Universtiy, China, in 2015. Her research interests include mechachonics engineering, machine transmission system. E-mail: hanling@ccut.edu.cn

Hui Zhang, born in 1995, is currently a master at Changchun University of Technology, China. He received his master degree on mechatronides in Changchun University of Technology, China, in 2018.

RuoYu Fang, born in 1995, is currently a master at Changchun University of Technology, China. He received his master degree on mechatronides in Jilin University, China, in 2018.

HongXiang Liu born in 1995, is currently a master at Changchun University of Technology, China. He received his master degree on mechatronides in Changchun University of Technology, China, in 2019.

\section{Corresponding author: Ling Han E-mail: hanling@ccut.edu.cn}




\title{
Optimization transmission efficiency with driver intention for automotive continuously variable transmission under slip mode
}

\author{
Ling Han ${ }^{1}$ Hui Zhang ${ }^{1}$ Ruo-Yu Fang ${ }^{1}$ Hong Xiang Liu ${ }^{1}$
}

Received June xx, 201x; revised February xx, 201x; accepted March xx, 201x

(c) Chinese Mechanical Engineering Society and Springer-Verlag Berlin Heidelberg 2017

\begin{abstract}
This study proposes and experimentally validates an optimal integrated system to control the automotive continuously variable transmission (CVT) to achieve its expected transmission efficiency range. The control system framework consists of top and bottom layers. In the top layer, a driving intention recognition system is designed on the basis of fuzzy control strategy to determine the relationship between the driver intention and CVT target ratio at the corresponding time. In the bottom layer, a new slip state dynamic equation is obtained considering slip characteristics and its related constraints, and a clamping force bench is established. Innovatively, a joint controller based on model predictive control (MPC) is designed taking internal combustion engine torque and slip between the metal belt and pulley as optimization dual targets. A cycle is attained by solving the optimization target to achieve optimum engine torque and the input slip in real-time. Moreover, the new controller provides good robustness. Finally, performance is tested by actual CVT vehicles. Results show that compared with traditional control, the proposed control improves vehicle transmission efficiency by approximately $9.12 \%-9.35 \%$ with high accuracy.
\end{abstract}

Keywords: V-belt Continuously variable transmission - Model predictive control $\bullet$ Drive intention $\bullet$ Slip mode Transmission efficiency

\section{Introduction}

Over the past decade, improving transmission efficiency

$\triangle$ Ling Han

hanling@ccut.edu.cn

1 School of Mechatronic Engineering, Changchun University of Technology, Changchun 130012, China and optimising power matching have become the main development trend of automatic transmission technology worldwide [1]. In this context, the continuously variable transmission (CVT) offers three benefits over other transmission vehicles [2, 3]. First, high efficiency leads to the best fuel economy curve by reducing transmission loss. Second, small transmission reduces the vehicle weight. Third, zero gear ratio gap can change the speed ratio continuously at a certain range [4]. Meanwhile, the fuel efficiency of CVT vehicle can increase by $10 \%-15 \%$ and harmful emission substances in automobile exhaust decreases by at least $10 \%$ [5]. Therefore, CVT is an ideal vehicle transmission equipment, which has received much attention and widely used in traditional and hybrid cars [6]. As such, in 2015, automobile companies such as Honda, Toyota, Ford and Volkswagen announced new technology roadmaps that takes CVT technology as the core development direction in the next 15 years. In 2019, CVT consolidated total sales have increased worldwide from 1.78 million in 2015 to 2.0 million in 2019 . In the next 20 years, over 2.6 million vehicles are expected to be equipped with CVT after improvements on existing technology, as shown in Figure 1 [7]. However, at present, the fuel economy of a vehicle metal belt CVT cannot reach the expected transmission efficiency range of 75\%-90\%. Several CVT advantages are offset by the required additional hydraulic power consumption of the clamping force acting on the pulleys, which is the root cause of the low efficiency [8]. For many years, the clamping force control strategy typically adopts the safety factor method, and the system is multiplied by a constant factor $\beta$ to satisfy CVT operation under any working conditions. However, while driving, this fixed control range cannot 
meet real-time road conditions and increases the wear between friction pairs [9].

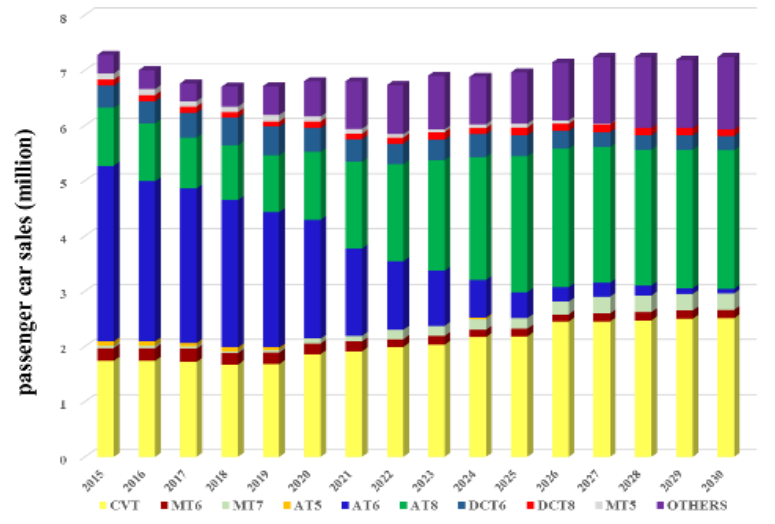

Figure 1 Total production of CVT worldwide from 2015 to 2030 Slip control is a new clamping force control method, adopted in the new generation of CVT to allow relative sliding between the belt and the pulleys. A certain degree of slip does not damage the metal belt and increases the friction factor, effectively reduces the clamping force, improves the transmission efficiency, and extends the service life of the CVT (in Figure 2) [10]. Thus, CVT not only tends to cause power loss in the metal belt but also (enlarged for clarity) severely affects the driving safety and vehicle service life. Determining the appropriate slip target is necessary, otherwise, the excessive slip rate can cause abrupt changes in the friction factor, increase the metal sheet wear, and even cause pulley slip failure. Therefore, controlling the slip rate of the metal belt in an ideal area is the key to improve the efficiency of CVT vehicles.

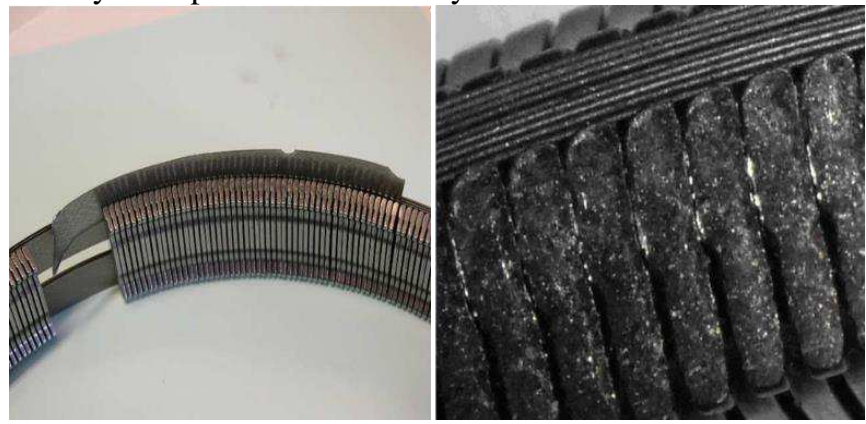

Figure 2 Failure of metal belt and metal sheet

For these reasons, recent research on improving automobile fuel economy widely vary [11]. Liu introduced a multi-range hydro-mechanical transmission to extend the gear ratio [12]. The torque limit under fixed clamping force is analysed through theoretical model and experiment [13], then the characteristics of the slip rate are studied. Controlling the slip rate within an appropriate range is expected to improve the transmission efficiency of the metal belt, but only from an engineering perspective [14]. Lei et al. [15] conducted a CVT transmission efficiency model base on bench test in which gasoline with low fuel consumption by measured, however, they ignored the influence of slip. The friction coefficient is expressed as a function of the ratio of the moving arc to the wrap angle of the pulley. Hiroyuki emphatically studied the slip boundary under input torque fluctuation [16]. The transmission loss caused by slip is also examined [17, 18] as applications of slip characteristics, but no study has delved into the theory of slip control. Therefore, this study develops a nonlinear and time-varying system of PID control [19], fuzzy control [20] and extremum seeking control [21] based on the optimal slip point to obtain the ideal clamping force in real time. Actual driving conditions are complex and changeable to retain the vehicle in its best state. Thus, accurate recognition of driver intention is necessary. However, many factors are not fully considered and the control results are not particularly ideal. The optimization effect can be improved, which is by determining the target speed ratio based on the accelerator pedal opening degree representing the driver intent, tracking control is added and the driving experience is verified according to different types of drivers [22-25]. This optimization method improves the transmission efficiency to a certain extent, but ignores the CVT advantages that can be combined with the engine to achieve joint optimization control and dramatically improve the transmission.

Currently, multi-objective control problems of complex nonlinear system in automotive research are widely solved using model predictive control (MPC) [26-28], because of its online prediction [29], rolling in real-time optimization [30, 31] and before and after feedback correction $[32,33]$.

In the present study, the main contributions can be summarised as follows.

(1) A novel engine and transmission joint control idea is proposed by considering the slip rate and driving intention, and a joint controller is designed based on MPC to improve the transmission efficiency.

(2) In the controller, ratio change rate and slip rate change are creatively taken as the state variables, and the ideal slip rate is used as the optimization tracking target.

(3) The intelligent optimization method by MPC can improve the efficiency for automotive of CVT by $9.12 \%$ $-9.35 \%$.

This paper is structured as follows. Section 2 presents the model and experiment for the belt CVT. Section 3 discusses the driver intention. Section 4 proposes the comprehensive optimization method in slip mode while Section 5 describes the drum test. Finally, Section 6 presents the conclusions. The diagram of overall control 
strategy is shown in the Figure 3.

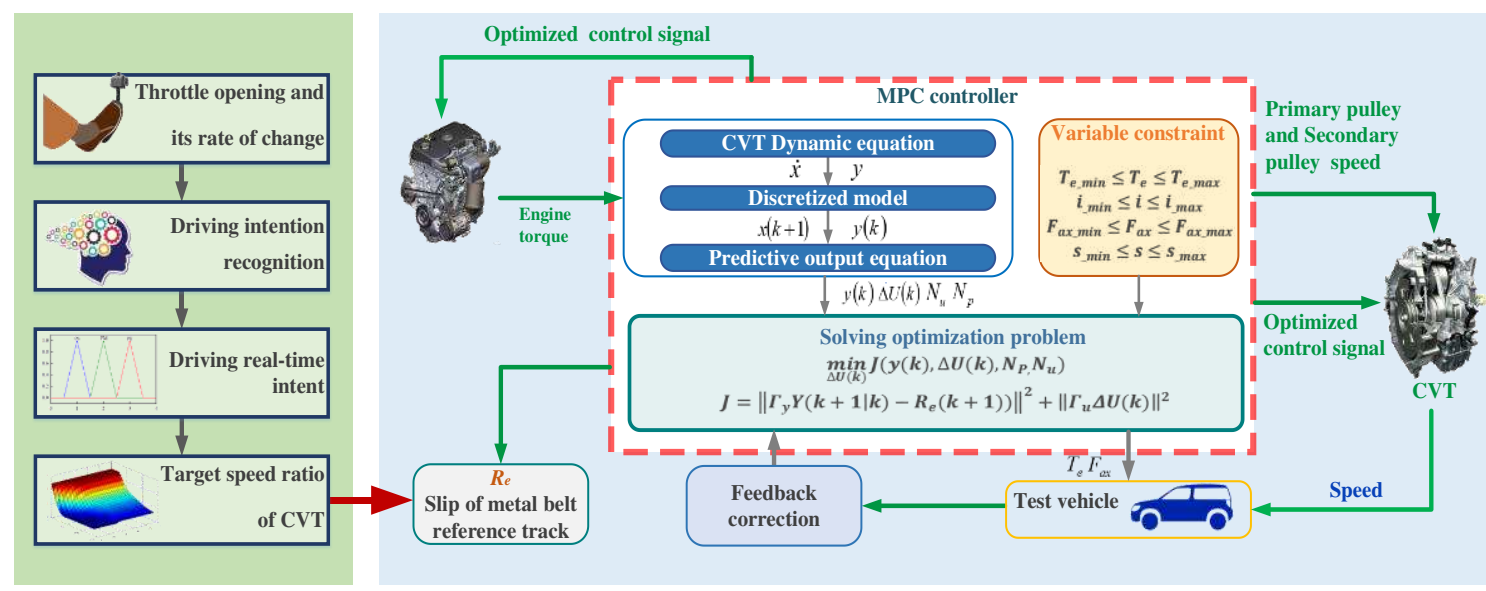

Figure 3 The diagram of overall control strategy

\section{Configuration of the Model and Experiment System}

The principle of CVT includes a speed change mechanism and a hydraulic system, in which the former is composed of two pulleys and metal belt that is clamped under the action of the hydraulic driving force to transmit torque. If the working radius is fixed, then the ability of the transmission mechanism to transmit torque is determined by the friction coefficient and the pulley. If the clamping force continues to decrease, then the friction between the metal belt and the cone surface of the pulley fails to meet the torque transmission requirements, resulting in slip between the pulleys. The degree of slip is described by the slip rate.

\subsection{Sliding Dynamic Model of CVT}

The vehicle transmission system is simplified to facilitate modelling. The transmission shaft connecting the two cone discs is regarded as a rod and the arrow direction is the positive direction of CVT. Figure 4 shows the CVT transmission.

The left side means inertia change of the powertrain and vehicle while the right side means net torque at output shaft. The dynamic equation is established and gear ratio change rate is also considered for precise control.

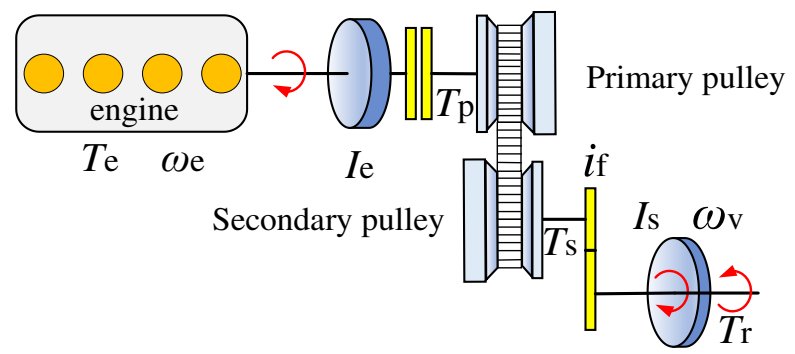

Figure 4 Transmission of CVT system

$$
\begin{aligned}
& T_{e}-T_{\text {in }}=I_{e} \dot{\omega}_{e} \\
& T_{\text {out }}=T_{\text {in }} i_{c v t} \eta_{c v t} \\
& T_{d}=T_{o u t} i_{0} \eta_{0} \\
& T_{d}-T_{r}=I_{v} \dot{\omega}_{v} \\
& T_{\text {in }}-T_{p}=J_{p} \dot{\omega}_{p} \\
& T_{s}-T_{o u t}=J_{s} \dot{\omega}_{s} \\
& \omega_{e}=\omega_{v} i_{c v t} i_{0}
\end{aligned}
$$

The relation between vehicle acceleration and change rate of speed ratio can be obtained by taking the derivative of Eq. (7) below.

$$
\dot{\omega}_{e}=i_{c v t} i_{0} \dot{\omega}_{v}+i_{0} \omega_{v} i_{c v t}
$$

Following Eq. (8) shows converting the model of CVT and Eqs. (1), (2) and (4) are implemented,

$$
i_{c v t}=\frac{T_{e}-T_{i n}}{I_{e} i_{0} \omega_{v}}-i_{c v t}\left(\frac{T_{d}-T_{r}}{I_{v} \omega_{v}}\right)
$$

where $T_{e}$ represents the engine torque; $T_{i n}$ is the input torque of transmission; $T_{\text {out }}$ is the output torque of transmission; $I_{e}$ is the flywheel moment of inertia; $i_{c v t}$ is the ratio of $\mathrm{CVT}$; $i_{0}$ is the ratio of main reducer $\eta_{c v t}$ is transmission efficiency of CVT; $\eta_{0}$ is transmission efficiency of main reducer; $T_{r}$ is driven shaft; $T_{d}$ is drive torque of wheels; $I_{v}$ is the equivalent moment of inertia of the output shaft; and $\omega_{v}$ is the wheel angular velocity. $\omega_{e}$ is the angular velocity of the engine crankshaft; and $\dot{\omega}_{e}$ is the engine crankshaft angular acceleration.

The actual speed ratio $i$ and theoretical speed ratio $i_{g}$ of CVT are defined by Eqs. (10)-(12).

$$
\begin{gathered}
i=\frac{\omega_{p}}{\omega_{s}} \\
i_{g}=\frac{R_{s}}{R_{p}}
\end{gathered}
$$

Combining Eqs. (10) and (11), the slip rate can be expressed as

$$
s=\frac{\omega_{p} R_{p}-\omega_{s} R_{s}}{\omega_{p} R_{p}}=1-\frac{i_{g}}{i}
$$

where $R_{p}$ and $R_{s}$ are the radii of passive and driving pulleys, respectively; $i_{g}$ and $i$ are the theoretical and actual speed ratios, respectively; and $\omega_{s}$ is the angular 
velocity of driving pulley; $\omega_{p}$ is the angular velocity of primary pulley.

The slip rate and speed ratio are obtained by derivations of Eqs. (13) and (14), respectively.

$$
\begin{aligned}
& \frac{d s}{d t}=\frac{i_{g}}{i^{2}} \frac{d i}{d t} \\
& \frac{d i}{d t}=\frac{\dot{\omega}_{p} \omega_{s}-\omega_{p} \dot{\omega}_{s}}{\omega_{s}^{2}}
\end{aligned}
$$

The dynamic equations of passive and driven pulleys of CVT are thus

$$
\begin{gathered}
\dot{\omega}_{p}=\frac{T_{\text {in }}-T_{p}}{J_{p}} \\
\dot{\omega}_{s}=\frac{T_{s}-T_{\text {out }}}{J_{s}}
\end{gathered}
$$

Friction theory posits that

$$
\begin{gathered}
T_{p}=\frac{2 F_{s} R_{p} \mu}{\cos \lambda} \\
T_{s}=\frac{2 F_{S} R_{S} \mu}{\cos \lambda}
\end{gathered}
$$

Substituting Eqs. (14)-(16) and Eqs. (17)-(18) into Eq. (13) can obtain Eq. (19), as

$$
\frac{d s}{d t}=\frac{1}{\omega_{p}}\left[-\frac{2 F_{s} R_{S} \mu(s) i_{g}}{J_{s} \cos (\lambda)}+\frac{T_{\text {out }} i_{g}}{J_{s}}\right]+\frac{(1-s)}{\omega_{p}}\left[-\frac{2 F_{S} R_{S} \mu(s)}{J_{p} \cos (\lambda)}+\frac{T_{\text {in }}}{J_{p}}\right]
$$

Where $T_{p}$ is the input torque of passive pulley and $T_{S}$ is the output torque of driving pulley; $J_{P}$ is a moment of inertia of the input and $J_{S}$ is a moment of inertia of the output; $\lambda$ is the cone angle between generatrix perpendicular and the axis of pulley surface; $F_{s}$ is the clamping force of driving pulley; $s$ is slip rate; and $\mu_{\mathrm{s}}$ is the variation function of friction factor with slip rate.

\subsection{Experimental Procedure}

The CVT transmission system independently developed by China is used as the research object. Figure 5 shows the designed clamping force test bench. During the test, the cylinder pressures of the passive and driven pulleys are assumed to be all closed-loop, controlled with a frequency of 100 hertz and a period of 20 milliseconds. The test is based on the following steps.

1. The target speed of the drive motor is 1000 RPM and the target torque is $40 \mathrm{Nm}$. Geometric speed ratio adopts mechanical limit method and fixed ratio position at 2.432 .

2. The pressure of the driven cylinder is reduced from 4.1 $\mathrm{MPa}$ to $0.1 \mathrm{MPa}$ intervals. The actual speed ratio, geometric speed ratio, transmission efficiency, and slip rate are then recorded. When the slip rate overtakes $4.5 \%$ as detected by TCU software that the system automatically enters the protection program state.

3 . Fix the geometric ratio to decrease from 2.432 to 0.419 . Then repeat step 2 .

4. Set the speed of the drive motor for 400 RPM intervals from 1000 RPM to 6000 RPM. Then, repeat steps
$1-3$.

5. Set the torque of the drive motor for $20 \mathrm{Nm}$ intervals from $40 \mathrm{Nm}$ to $130 \mathrm{Nm}$. Then repeat steps $1-4$.

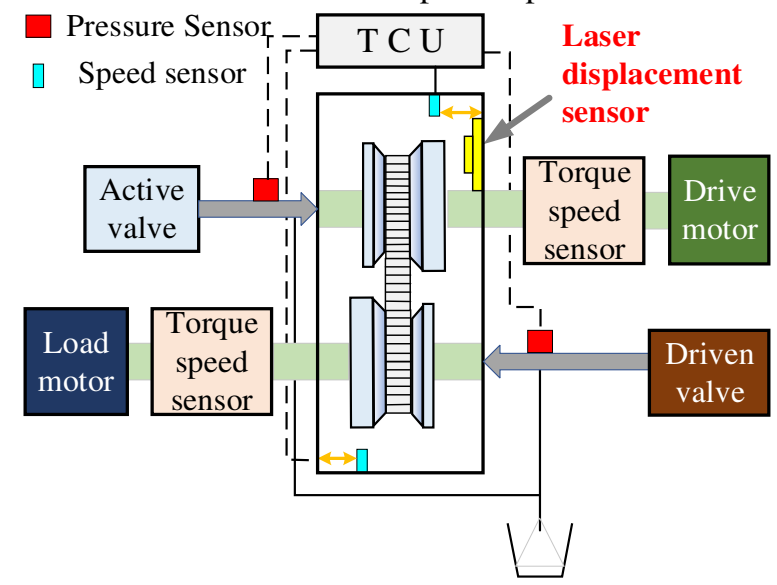

Figure 5 Diagram of clamping force bench test

The entire process is analysed through the above test, and the best slip rate and ratio of each point are fitted to form the best slip curve in Figure 6 .

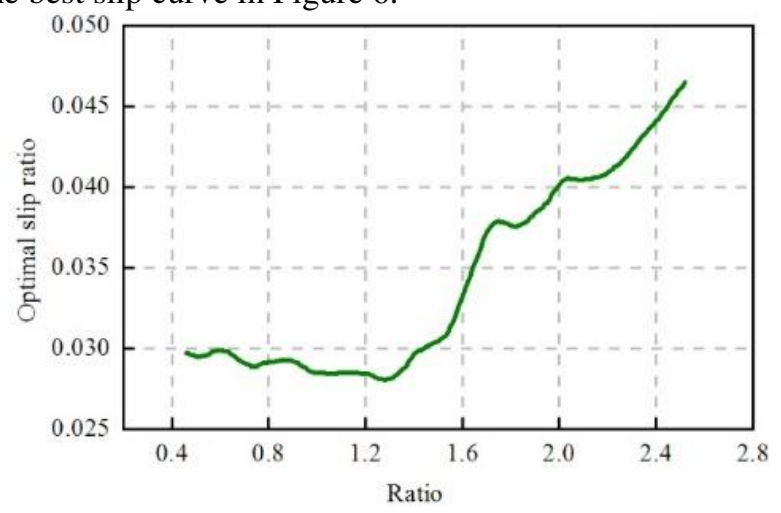

Figure 6 Relationship between optimal slip and ratio

When the slip rate is small, the slip rate and the friction coefficient show a linear proportional relationship, that is, the friction coefficient increases with the slip rate. When the friction coefficient reaches its peak and gradually declines, the slip rate continues to increase. Therefore, the optimal slip rate corresponds to the maximum friction coefficient at different speed ratios, and can be obtained by crossing the full ratio ranges and dividing equally, fitting the optimal slip ratio data at different ratios.

\section{Driver Intent Decision}

\subsection{Engine Model}

A 1.48 L, 4-cylinder engine is used for this research. The engine efficiency and torque within the range 500-6000 RPM and 30-134 Nm, respectively. Relevant data are obtained from the engine steady state test and used to determine the shape of the fuel consumption map. Figure 7 shows a 3D representation of the steady-state engine 
output torque model. With the aim to avoid multiple local maxima in the initial data set, the cubic spline interpolation method is used to smooth the parameters and obtain a working surface while retaining realistic characteristics within the numerical optimization. Figure 8 shows a 3D representation of the engine map.

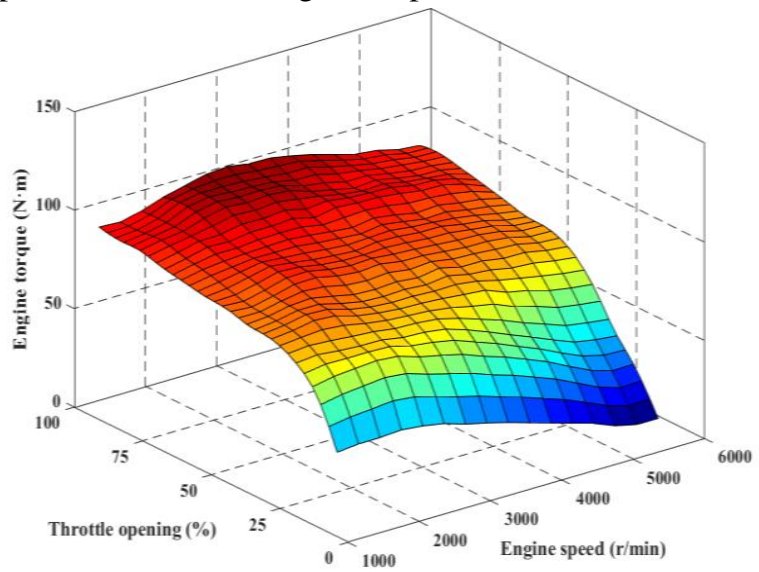

Figure 7 Steady-state engine fuel consumption map

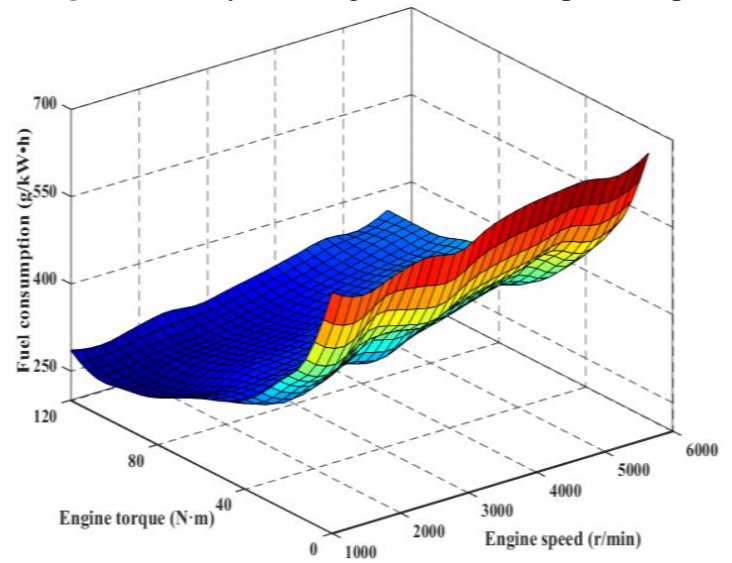

Figure 8 Engine output torque model

However, the output characteristics of the engine is affected by the change of the mixture concentration. The engine under unsteady state condition differs from steady conditions, thereby the correction coefficient $\gamma$ is introduced to modify the engine torque. Eq. (20) obtains the modified dynamic output torque as

$$
T_{e}=T_{e w}\left(1-\gamma \frac{d \omega_{e}}{d t}\right)
$$

where $T_{e w}$ is the steady-state output torque of the engine and $\gamma$ is the torque drop coefficient (0.08).

\subsection{Identify Driver Intention}

CVT efficiency is determined using bench test data and is most dependent on CVT ratio. When the vehicle throttle opening is constant, the ratio is precisely controlled to ensure that the engine output power and running resistance can be optimally matched according to the driver intention in real time. Eq. (21) obtains the CVT ratio as

$$
i=\frac{R_{S}}{R_{p}}=\frac{n_{\text {in }}}{n_{\text {out }}}
$$

where $n_{\text {in }}$ is input shaft speed and $n_{\text {out }}$ is output shaft speed. The maximum and minimum ratios applied to the CVT are

$$
\begin{aligned}
i & ={\frac{R_{S_{\_} \max }}{R_{p_{\_} \min } \text { max }}}_{i}={\frac{R_{S_{\_} \text {min }}}{R_{p_{-} \text {max }}}}_{\text {min }}
\end{aligned}
$$

Three constraints come from restricting the CVT target ratio, which are

$$
i_{\text {obj }}=\left\{\begin{array}{cc}
i_{\text {max }} & \left(n_{\text {in }} / n_{\text {out }}>i_{\text {max }}\right) \\
n_{\text {in }} / n_{\text {out }} & \left(i_{\text {max }}>n_{\text {in }} / n_{\text {out }}>i_{\text {min }}\right) \\
i_{\text {min }} & \left.\left(n_{\text {in }} / n_{\text {out }}<i_{\text {max }}\right)\right)
\end{array}\right.
$$

The ratio can also be expressed in Eq. (25),

$$
i=\frac{0.377 r_{w} n_{e}}{v i_{0}}
$$

where $r_{w}$ is the wheel radius; $n_{e}$ is engine speed; and $v$ is driving speed.

The equations of the target rate constraint applied in the movement structure and the shift rate limits are a function of CVT ratio, as shown in Figure 9.

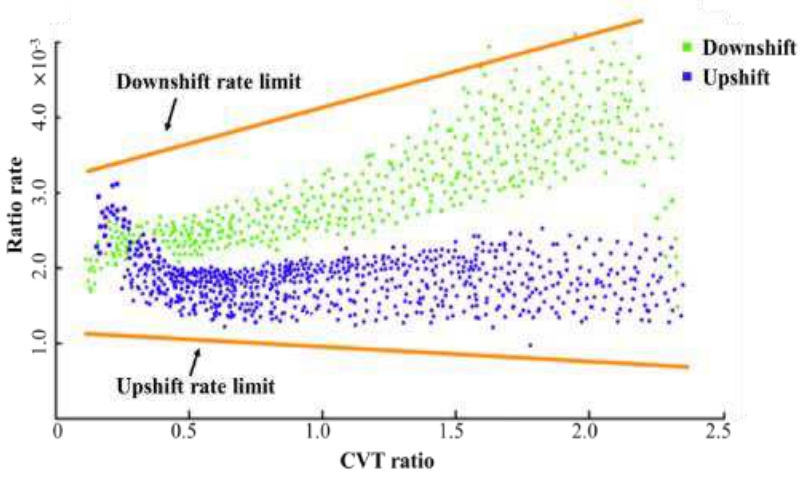

Figure 9 Shift rate limits of CVT ratio

Thus, the engine throttle opening and vehicle speed are fixed. Figures 10-11 show two 3D representations of the best economy and dynamic of target ratio maps.

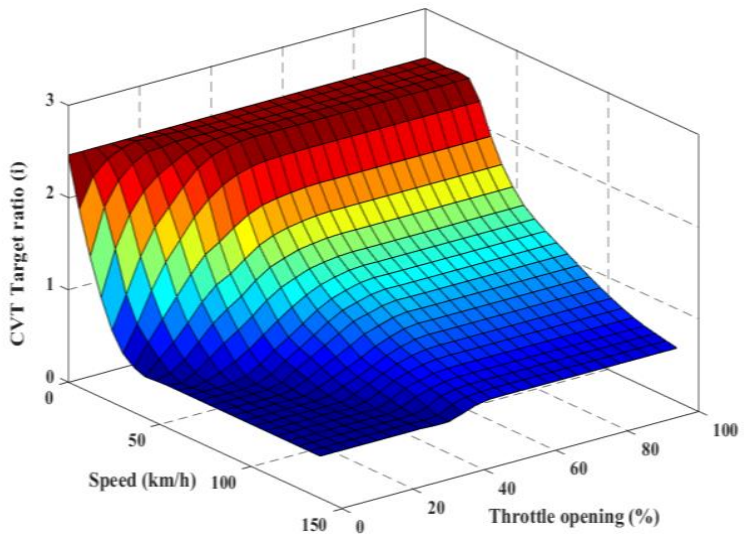


Figure 10 3D representation of the best economy of target ratio

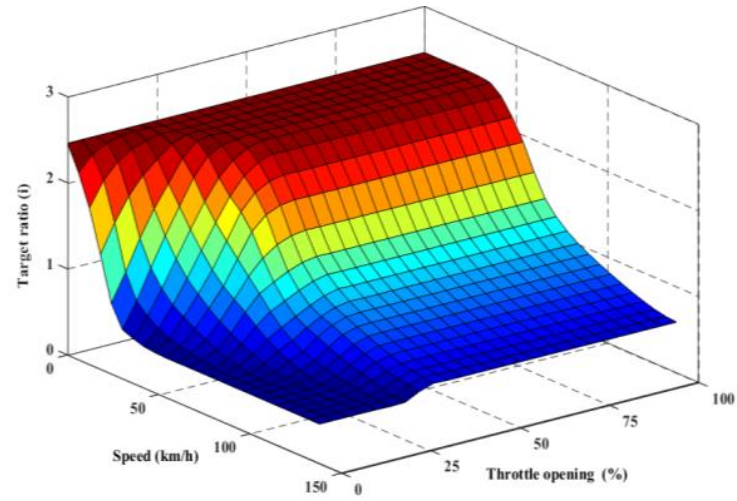

Figure 11 3Drepresentation of the best dynamic of target ratio The driver's evaluation of the vehicle driving performance is subjective, and reflects the degree of conformity for the actual vehicle response and driver expectations. Different driving habits and operating conditions have varied requirements for vehicle driving performance. However, in general, driver expectations of vehicle response can be described as smooth and fast input response to throttle opening, consistent with expected psychological expectations, and repeatable. Therefore, the dynamic and economic mode alone cannot fully reflect the driver intention in real time. Determining the target ratio of the vehicle in standard mode is necessary. The target engine speed in standard mode can be expressed as Eq. (26)

$$
n_{m e}=k\left(n_{s e}-n_{e e}\right)+n_{e e}
$$

where $n_{m e}$ is the target ratio of engine in standard mode; $n_{s e}$ is the target ratio of engine in dynamic mode; $n_{e e}$ is the target ratio of engine in economic mode; and $k$ is intent parameter of driving set between $0-1$ to change continuously. Figure 12 shows the target engine speed.

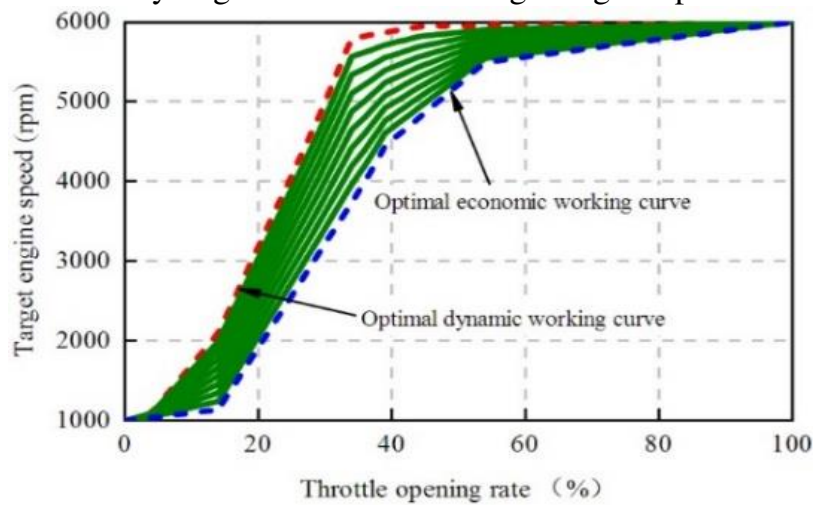

Figure 12 Engine speed regulation characteristic

Table 1 Fuzzy inference rules curve in standard mode

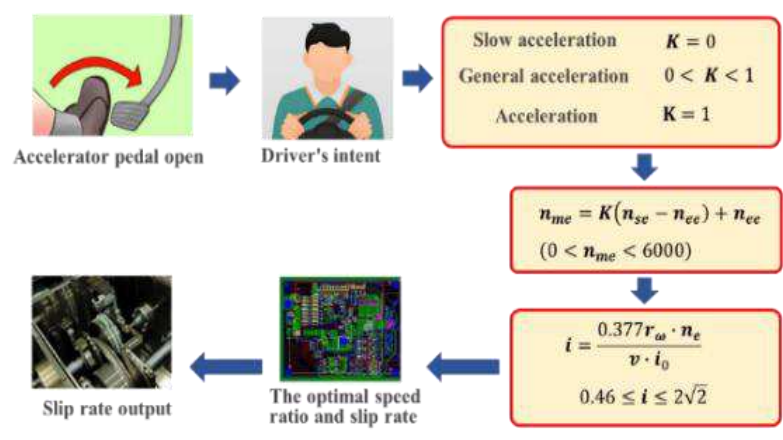

Figure 13 Driver intent

In actual driving, the accelerator pedal opening change rate can better reflect the driver's real-time demand for vehicle dynamics. Therefore, the driving intention parameter can be expressed as

$$
k=f(d \theta / d t) \quad(0<k<1)
$$

where $\theta$ is accelerator pedal opening.

Vehicle acceleration is slow when $k=0$ and general when $0<k<1$. Figure 13 shows the driver's operating intention when vehicle acceleration is $k=1$.

The accelerator pedal opening degree and its rate of change are selected as the basis for recognition of acceleration intention. When the vehicle brakes or decelerates, the driver has no demand for the vehicle power, and the engine working curve is assumed equivalent to the best economic curve. The input accelerator pedal opening and rate of change and the output variable acceleration intention are blurred. The domain of accelerator pedal opening is set as [0, 100] and the corresponding fuzzy subset is $\{\mathrm{PS}, \mathrm{PM}, \mathrm{PB}\}$. The domain of rate change of accelerator pedal opening is set as $[-100,100]$ and the corresponding fuzzy subset is $\{\mathrm{N}, \mathrm{PS}, \mathrm{PM}, \mathrm{PB}\}$. The corresponding fuzzy subset of the accelerator pedal opening of input and its rate of change is $\{\mathrm{PS}, \mathrm{PM}, \mathrm{PB}\}$. Figure 13 shows the membership function. Final fuzzy inference system uses the Mamdani algorithm and centre of gravity method for back fuzzy. Table 1 shows the fuzzy inference rules. 


\begin{tabular}{|c|c|c|c|c|c|}
\hline \multirow[t]{2}{*}{ Item } & \multicolumn{5}{|c|}{$\begin{array}{c}\text { Change of rate for accelerator pedal } \\
\text { opening displacement }\end{array}$} \\
\hline & & $\mathrm{N}$ & PS & $\mathrm{PM}$ & $\mathrm{PB}$ \\
\hline Accelerator & PS & PS & PS & $\mathrm{PM}$ & $\overline{P B}$ \\
\hline Pedal & PM & PS & PM & PM & PB \\
\hline Displacement & PB & PS & PM & PB & PB \\
\hline
\end{tabular}

Figures 14-15 show the vehicle rate of change for accelerator pedal opening curve and recognition result of driver intention, respectively, to simulate and verify the driving intent model. Figure 11 shows that in $0-25 \mathrm{~s}$, the accelerator pedal opening increases from $0 \%$ to $30 \%$, then remains steady with rate change maintained at $5 \% / \mathrm{s}$ within 0-15 s. The accelerator pedal opening remains unchanged and returns to $0 \% / \mathrm{s}$ within $15-25 \mathrm{~s}$. In $25-34 \mathrm{~s}$, the accelerator pedal opening increases from $30 \%$ to $45 \%$, then remains steady with rate change maintained at $12.5 \% / \mathrm{s}$ within 25-28 s. The accelerator pedal opening remains unchanged and returns to $0 \% / \mathrm{s}$ within $15-25 \mathrm{~s}$. In $34-35.5$ $\mathrm{s}$, the accelerator pedal opening decreases from $45 \%$ to $15 \%$ with rate change maintained at $-48 \% / s$, then remains unchanged. In 44-50 s, the accelerator pedal opening increases to $57 \%$ then remains steady at $35.5 \% / \mathrm{s}$ and decreases to $0 \% / \mathrm{s}$.

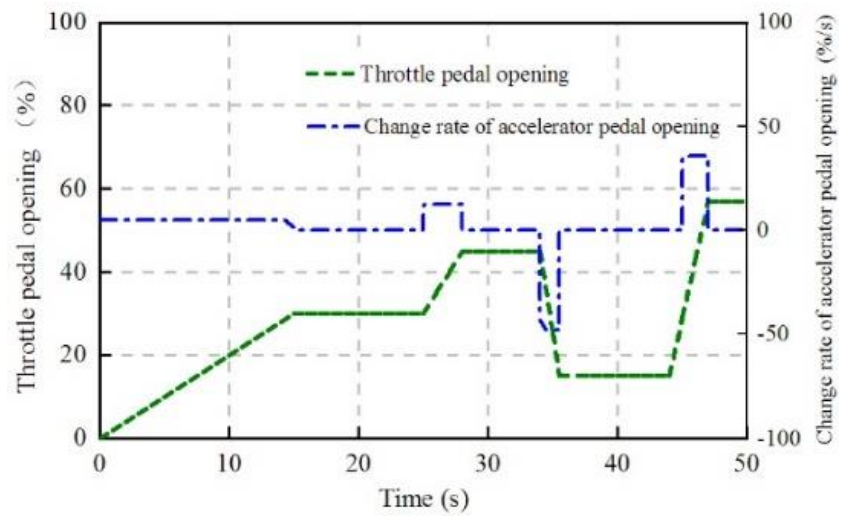

Figure 14 Curve of the accelerator pedal opening and its change

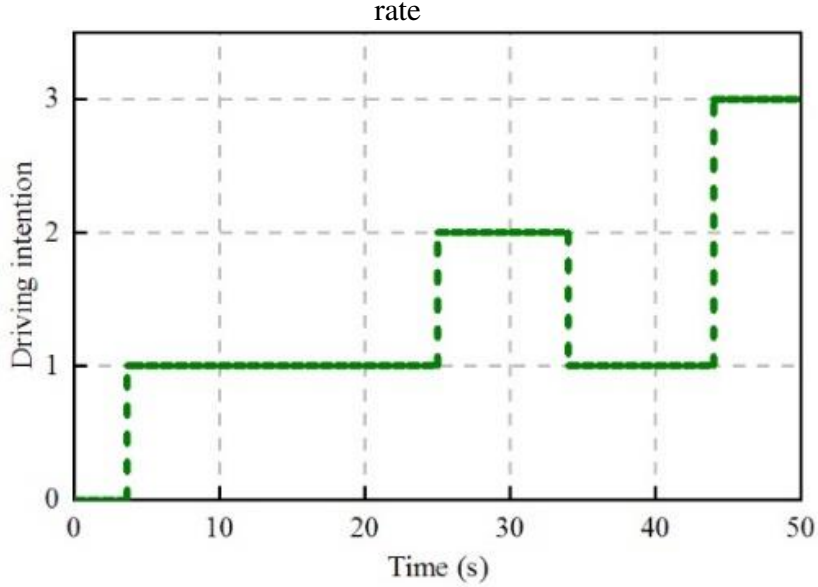

Figure 15 Result of driving intention recognition

The vehicle accelerator pedal opening and its change rate are: small between $0-25 \mathrm{~s}$ and $34-44 \mathrm{~s}$, with slow acceleration; increases between 25-34 s, with general acceleration; and large between 44-50 s, with emergency acceleration. According to the above acceleration recognition results, the controller accurately recognises the driver intention, and fuzzy controller has good effectiveness.

\section{Proposed Comprehensive Optimization Method in Slip Mode}

\subsection{State Space Equation of CVT}

The $\operatorname{slip} s$ and ratio $i$ are defined as state variables $x$; clamping force $F_{s}$ and torque of engine $T_{e}$ are controlled to output as $u$; slip $s$ and ratio $i$ are predicted to output as $y$; and input torque $T_{\text {in }}$ and output torque $T_{\text {out }}$ of CVT are disturbance variables $d$. The incremental model is as follows,

$$
\begin{gathered}
\dot{x}(t)=A x(t)+B u(t)+B_{d} d(t) \\
y(t)=C x(t)
\end{gathered}
$$

where

$x=\left[\begin{array}{ll}i & s\end{array}\right]^{T}$;

$u=\left[\begin{array}{ll}F_{S} & T_{e}\end{array}\right]^{T}$;

$y=\left[\begin{array}{ll}i & s\end{array}\right]^{T}$;

$d=\left[\begin{array}{ll}T_{\text {in }} & T_{\text {out }}\end{array}\right]^{T}$;

$A=\left[\begin{array}{cc}\frac{T_{r}-T_{d}}{I_{v} \omega_{v}} & 0 \\ 0 & \frac{2 F_{S} R_{S} \mu(s)}{J_{p} \omega_{p} \cos (\lambda)}-\frac{T_{i n}}{J_{p} \omega_{p}}\end{array}\right] ;$

$B=\left[\begin{array}{cc}0 & \frac{1}{I_{e} i_{0} \omega_{v}} \\ \frac{-2 R_{s} \mu(s) i_{g}}{J_{s} \omega_{p} \cos (\lambda)}+\frac{-2 R_{S} \mu(s)}{J_{p} \omega_{p} \cos (\lambda)} & 0\end{array}\right]$;

$B_{d}=\left[\begin{array}{cc}-\frac{1}{I_{e} i_{0} \omega_{v}} & 0 \\ \frac{1}{J_{p} \omega_{p}} & \frac{i_{g}}{J_{s} \omega_{p}}\end{array}\right]$

$C=\left[\begin{array}{ll}1 & 0 \\ 0 & 1\end{array}\right]$.

The linearized friction coefficient $\mu(s)$ can be expressed as Eq. (28) to facilitate the controller design.

$$
\mu(s)=k_{1} s+k_{2}
$$

The CVT state space equation is linearized at $x=s_{0}$ as the operating point,

$$
\begin{gathered}
\delta \dot{x}(t)=A_{0} \delta x(t)+B_{0} \delta u(t)+B_{d 0} \delta d(t) \\
\delta y(t)=C_{0} \delta x(t)
\end{gathered}
$$

where $\delta x=x-x_{0} ; \delta u=u-u_{0} ; \delta d=d-d_{0}$. 


\subsection{Joint Controller Design}

The controller is realised by discretising the state space equation for the sampling period $T_{s}$,

$$
\begin{gathered}
x(k+1)=A_{c} x(k)+B_{c} u(k)+B_{d c} d(k) \\
y(k)=C x(k)
\end{gathered}
$$

where $A_{c}=e^{A T_{s}} ; B_{c}=\int_{0}^{T_{S}} e^{A \tau} d s \cdot B$;

$B_{d c}=\int_{0}^{T_{s}} e^{A \tau} d s \cdot B_{d}$.

Integral is introduced to eliminate the static error generated during the clamping force control, and the discretised state model is rewritten as the following incremental model forms,

$$
\begin{gathered}
\Delta x(k+1)=A_{c} \Delta x(k)+B_{c} \Delta u(k)+B_{d c} \Delta d(k) \\
y(k)=C \Delta x(k)+y(k-1)
\end{gathered}
$$

where

$\Delta x(k)=x(k)-x(k-1)$

$\Delta u(k)=u(k)-u(k-1)$

$\Delta d(k)=d(k)-d(k-1)$.

The prediction and control time domains are defined as $N_{p}=10, N_{u}=2$, respectively.

Using $\Delta x(k)$ as the starting point for the prediction of the system, the state at times $k+1$ to $k+N_{p}$ can be predicted as:

$$
\begin{aligned}
& \Delta x(k+1 \mid k)=A_{c} \Delta(k)+B_{c} \Delta u(k)+B_{d c} \Delta d(k) \\
& \Delta x(k+2 \mid k)=A_{c} \Delta(k+1 \mid k)+B_{c} \Delta u(k+1)+B_{d c} \Delta d(k \\
& +1) \\
& =A_{c}^{2} \Delta x(k)+A_{c} B_{c} \Delta u(k)+B_{c} \Delta u(k+1)+A_{c} B_{d c} \Delta d(k) \\
& \Delta x(k+3 \mid k)=A_{c} \Delta x(k+2 \mid k)+B_{c} \Delta u(k+2) \\
& +B_{d c} \Delta d(k+2) \\
& =A_{c}^{3} \Delta x(k)+A_{c}^{2} B_{c} \Delta u(k)+A_{c} B_{c} \Delta u(k+1)+B_{c} \Delta u(k \\
& +2)+A_{c}^{2} B_{d c} \Delta d(k) \\
& \mathrm{N} \\
& \Delta x\left(k+N_{u} \mid k\right)=A_{c} \Delta x\left(k+N_{u}-1 \mid k\right)+B_{c} \Delta u\left(k+N_{u}\right. \\
& -1)+B_{d c} \Delta d\left(k+N_{u}-1\right) \\
& =A_{c}^{N_{u}} \Delta x(k)+A_{c}^{N_{u}-1} B_{c} \Delta u(k)+A_{c}^{N_{u}-2} B_{c} \Delta u(k+1) \\
& +\cdots \\
& +B_{c} \Delta u(k+m-1)+A_{c}^{N_{u}-1} B_{d c} \Delta d(k) \\
& \mathrm{N} \\
& \Delta x\left(k+N_{p} \mid k\right)=A_{c} \Delta x\left(k+N_{p}-1 \mid k\right)+B_{c} \Delta u\left(k+N_{p}\right. \\
& -1)+B_{d c} \Delta d\left(k+N_{p}-1\right) \\
& =A_{c}^{N_{p}} \Delta x(k)+A^{N_{p}-1} B_{c} \Delta u(k)+A_{c}^{N_{p}-2} B_{c} \Delta u(k+1)+\cdots \\
& +A_{c}^{N_{p}-N_{u}} B_{c} \Delta u\left(k+N_{u}-1\right)+A_{c}^{N_{p}-1} B_{d c} \Delta d(k)
\end{aligned}
$$

where $k+i \mid k$ represents the prediction of $k+i$ at sampling time $k$, and $k$ after the symbol "|" represents the current sampling time.

Similarly,

$$
\begin{gathered}
y(k+1 \mid k)=C \Delta x(k+1 \mid k)+y(k) \\
=C A_{c} \Delta x(k)+C B_{c} \Delta u(k)+C B_{d c} \Delta d(k)+y(k) \\
y(k+2 \mid k)=C \Delta x(k+2 \mid k)+y(k+1 \mid k) \\
=\left(C A_{c}^{2}+C A_{c}\right) \Delta x(k)+\left(C A_{c} B_{c}+C B_{c}\right) \Delta u(k)+ \\
C B_{c} \Delta u(k+1)+\left(C A_{c} B_{d c}+C B_{d c}\right) \Delta d(k)+y(k)
\end{gathered}
$$

$\mathrm{N}$

$$
\begin{aligned}
& y\left(k+N_{u} \mid k\right)=C \Delta x\left(k+N_{u} \mid k\right)+y\left(k+N_{u}-1 \mid k\right) \\
& =\sum_{i=1}^{N_{u}} C A_{c}^{i} \Delta x(k)+\sum_{\substack{i=1 \\
N_{u}-1}}^{N_{u}} C A_{c}^{i-1} B_{c} \Delta u(k) \\
& +\sum_{i=1}^{N_{u}-1} C A_{c}^{i-1} B_{c} \Delta u(k+1)+\cdots \\
& +C B_{c} \Delta u\left(k+N_{u}-1\right)+\sum_{i=1}^{N_{u}} C A_{c}^{i-1} B_{d c} \Delta d(k)+y(k) \\
& \mathrm{N} \\
& y\left(k+N_{p} \mid k\right)=C \Delta x\left(k+N_{p} \mid k\right)+y\left(k+N_{p}-1 \mid k\right) \\
& =\sum_{i=1}^{N_{p}} C A_{c}^{i} \Delta x(k)+\sum_{\substack{i=1 \\
N_{p}-1}}^{N_{p}} C A_{c}^{i-1} B_{c} \Delta u(k) \\
& +\sum_{i=1}^{N_{p}-1} C A_{c}^{i-1} B_{c} \Delta u(k+1)+\cdots \\
& +\sum_{i=1}^{N_{p}-N_{u}+1} C A_{c}^{i-1} B_{c} \Delta u\left(k+N_{u}-1\right) \\
& +\sum_{i=1}^{N_{p}} C A_{c}^{i-1} B_{d c} \Delta d(k)+y(k)
\end{aligned}
$$

At sampling time $k$, the control input vector $\Delta U(k)$ and the predicted output vector $Y(k+1 \mid k)$ are defined as:

$$
\begin{gathered}
\Delta U(k)=\left[\begin{array}{c}
\Delta u(k \mid k) \\
\Delta u(k+1 \mid k) \\
\vdots \\
\Delta u\left(k+N_{u}-1 \mid k\right)
\end{array}\right] \\
Y(k+1 \mid k)\left[\begin{array}{c}
y(k+1 \mid k) \\
y(k+2 \mid k) \\
\vdots \\
y\left(k+N_{p} \mid k\right)
\end{array}\right]
\end{gathered}
$$

Where,

$$
\begin{aligned}
& \Delta u(k+i \mid k)=\left[\begin{array}{l}
\Delta F_{s}(k+i \mid k) \\
\Delta T_{e}(k+i \mid k)
\end{array}\right], i=1,2, \cdots, N_{u}-1 \\
& y(k+i \mid k)=\left[\begin{array}{l}
i(k+i \mid k) \\
S(k+i \mid k)
\end{array}\right], \quad i=1,2, \cdots, N_{p} .
\end{aligned}
$$

The reference input sequence can be defined as

$$
R_{e}(k+1)=\left[\begin{array}{llll}
r(k+1) & r(k+2) & \cdots & r\left(k+N_{p}\right)
\end{array}\right]^{T}
$$

Where, $r(k+i)=s(k+i), i=1,2, \cdots, N_{p}$.

Given the theoretical basis of model predictive control, the clamping force optimization problem can be described as the following objective function,

$$
\begin{gathered}
\min _{\Delta U(k)} J\left(y(k), \Delta U(k), N_{u}, N_{p}\right) \\
J=\left\|\Gamma_{y}\left(Y(k+1 \mid k)-R_{e}(k+1)\right)\right\|^{2}+\left\|\Gamma_{u} \Delta U(k)\right\|^{2} \\
\text { Where, } \\
\Gamma_{y}=\operatorname{diag}\left\{\gamma_{y, 1}, \cdots, \gamma_{y, N_{p}}\right\} ; \Gamma_{u}=\operatorname{diag}\left\{\gamma_{u, 1}, \cdots, \gamma_{u, N_{u}}\right\} .
\end{gathered}
$$


The slip rate tracking effect of the clamping force controller can be changed by adjusting the error weight coefficient $\Gamma_{y}$, setting $\gamma_{y, i}=0.13, i=1,2, \cdots, N_{p}$. The change rate of the clamping force can be controlled to prevent the actuator from reaching the saturation state by adjusting the control weight coefficient $\Gamma_{u}$. Set $x$ as the reference input of the slip rate as $\gamma_{u, i}=1, i=1,2, \cdots, N_{u}$, $R_{e}(k+1)$.

Defined,

$$
\begin{gathered}
J_{1}=\| \Gamma_{y}\left(Y(k+1 \mid k)-R_{e}(k+1) \|^{2}\right. \\
J_{2}=\left\|\Gamma_{u} \Delta U(k)\right\|^{2}
\end{gathered}
$$

$J_{1}$ represents the square weighted value of the difference between the actual measured slip rate in the predicted time domain and the reference input and $J_{2}$ represents the square-weighted value of the amount of clamping force change in the control time domain.

Three more constraints arise from restricting the clamping force controller between a maximum and minimum predefined variable.

$$
\begin{gathered}
T_{e_{-} \min } \leq T_{e} \leq T_{e \_ \text {max }} \\
i_{\_ \text {min }} \leq i \leq i i_{-\max } \\
F_{\text {ax_min }} \leq F_{a x} \leq F_{\text {ax_max }} \\
S_{\_ \text {min }} \leq s \leq S_{\_} \text {max }
\end{gathered}
$$

The constrained objective function is applied to obtain the final optimization result.

\subsection{Joint Controller Design Simulation Model}

Figures 16-17 shows simulation models built on MATLAB/SIMULINK and AMESim platforms. Simulink includes clamping force control, speed ratio control and engine. AMESim includes CVT, vehicle, slip and hydraulics. The simulation model shows that the clamping force control module based on MPC inputs the optimised clamping force control signal to its valve through the rotary interface. Clamping is realised by controlling the secondary pulley cylinder control of precise force. The PID-based speed ratio control module applies the optimised ratio signal to its valve.

The closed-loop control experiment of the clamping force system is carried out based on the above-mentioned controller design principle. In Figure 18, the driving motor torque is $45 \mathrm{Nm}$, speed ratio is 0.45 and the stable speed is $1600 \mathrm{r} / \mathrm{min}$.

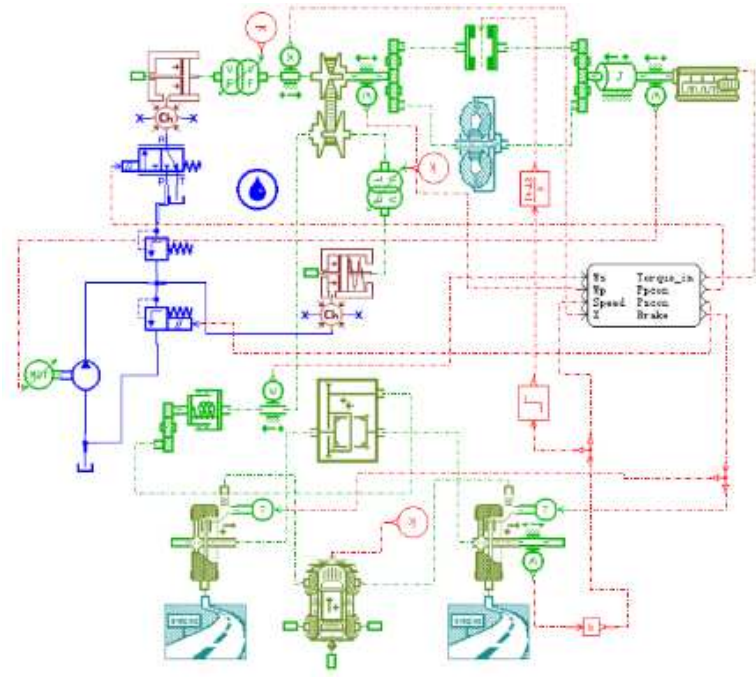

Figure 16 Controller simulation in AMESim

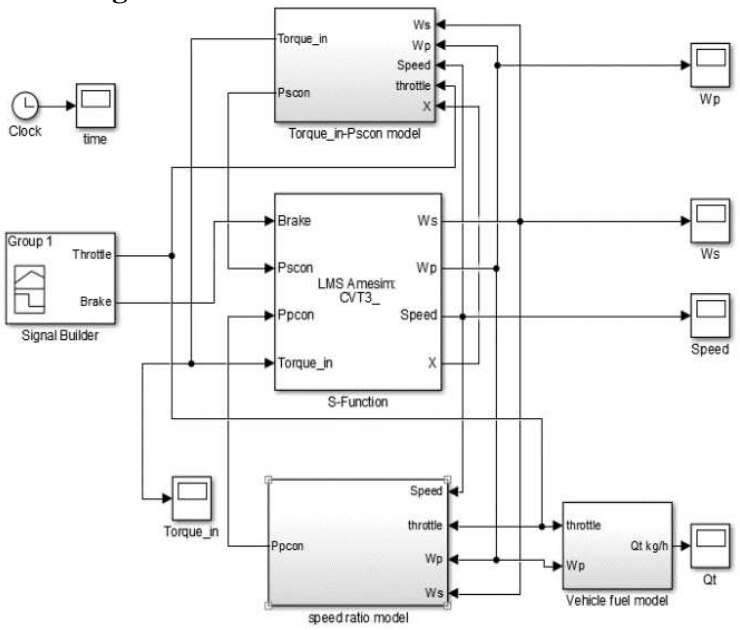

Figure 17 Controller simulation in MATLAB/SIMULINK
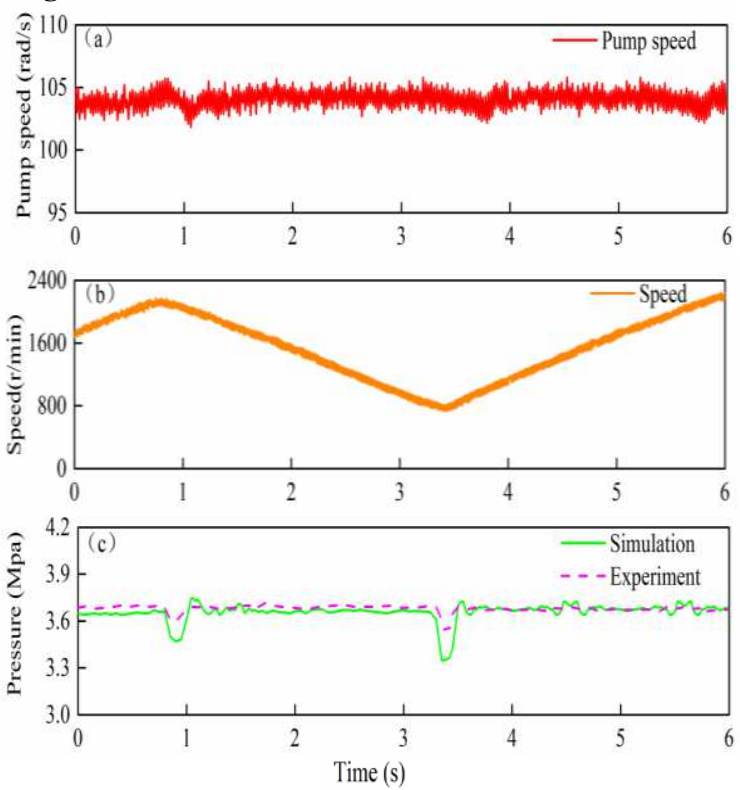

Figure 18 (a) Pump speed (b) Speed (c) Pressure During the step response test, maintain the pump speed 
and the driving shaft constant, the actual speed fluctuates around the controlled target value in (a). According to the results, with the step input of the driving current of the lead solenoid valve, the speed of

\subsection{Robust Verification}

Based on the MPC control strategy, the torque interference on the active side mainly depends on the engine operating conditions and road surface conditions, which are divided into continuous and non-continuous interferences. Typical operating conditions of continuous interference include the vehicle transition from flat road to hill climbing sections, or from smooth to rough roads. Non-continuous disturbances include torque shocks caused by vehicles passing through potholes or avoiding obstacles.

The robust performance analysis of the CVT system mainly depends on the system stability after a disturbance. Therefore, robust verification of the control system is necessary under non-steady-state condition. The robust verification is achieved by simulating the driver quickly stepping on the accelerator pedal to maintain speed and then lifting the pedal. The engine generates step torque that remains unchanged and decreases, the value can be read directly through the engine MAP.

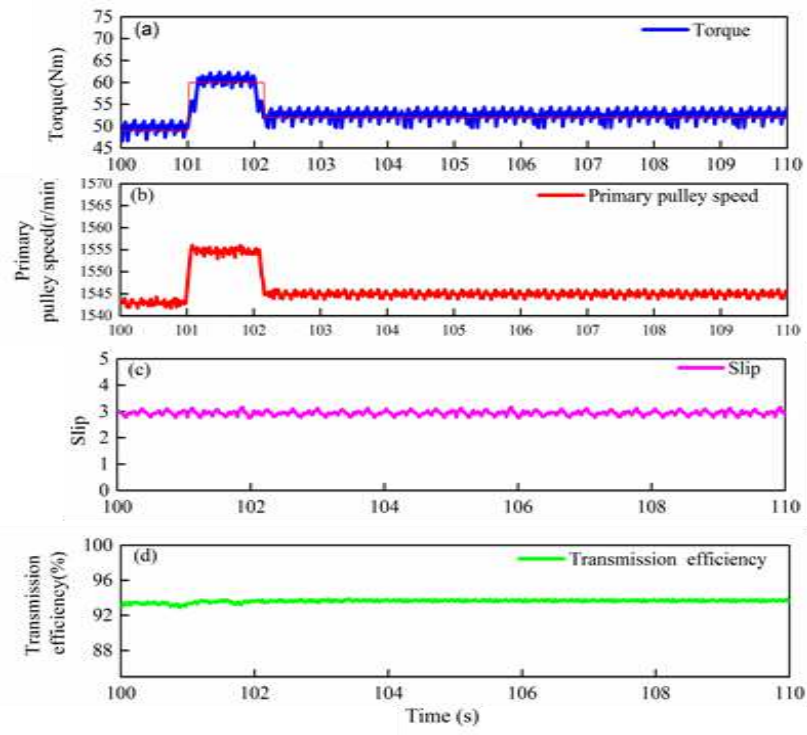

Figure 19 (a) Input side torque step interference (b) Speed of primary pulley (c) Slip (d) CVT transmission efficiency

The robustness of the control system is further analysed. Figure 19 shows that a certain torque disturbance factor is imposed from the outside. The input side torque step disturbance in (a) shows that between 100-101 s, the torque is relatively stable without apparent fluctuations. When $\mathrm{t}=101 \mathrm{~s}$, a stepping torque of $13 \mathrm{Nm}$ shock is imposed. The input side torque produces a corresponding step change, and the torque rises from the initial value of the primary pulley shaft shows a saw tooth change similar to a sinusoid (b). Moreover, comparison of the pressure response of the hydraulic system shows a good consistency of the test and simulation results (c).

50-63 Nm. At $102 \mathrm{~s}$, a decrease of $7 \mathrm{Nm}$ step torque on CVT input side maintains the torque at $53 \mathrm{Nm}$. Under the MPC, the clamping force is pre-controlled by loading a certain clamping force according to the sudden torque change. The transmission mechanism can provide the additional torque. Therefore, the active side speed rises first in the control system, and then quickly stabilises. Figure 18 (b) shows the speed of primary pulley. After the cylinder pressure changes, the actual response follows the dynamic response faster and operates steadily with changes in external torque interference. (c) and (d) show the changes of the slip and transmission efficiency when the torque disturbance on the input side, respectively. When the CVT input side is subjected to torque disturbance, the transmission efficiency and slip generally perform smoothly, the transmission efficiency only slightly fluctuates at the torque step, the slip is always kept within the safety threshold, and thus the transmission system remains stable. Given the above test results, the CVT control system designed in MPC has good robust performance.

\subsection{Simulation and Analysis of Control System}

On the basis of robust performance test analysis, the controller designed based on the model predictive control strategy and the safety factor method control strategy is compared and tested under NEDC cycle conditions to ensure reliability and consistency. The NEDC cycle is composed of urban areas, suburbs and highways. The test content includes the CVT pulley speed, slip, vehicle instantaneous fuel consumption rate, ratio, secondary pulley pressure and engine torque. Figure 20 shows the results. (a) and (f) show the CVT primary and secondary pulley speed and engine torque under NEDC cycle conditions at different times. Changes in speed and engine torque are observed. (b) is the slip, where the actual slip can better track the target slip during the test and meet the vehicle control requirements. (c) shows the instantaneous vehicle fuel consumption rate. The fuel consumption corresponding to the controller based on the MPC is 7.26 $\mathrm{L} / 100 \mathrm{~km}$, which decreases by approximately $5.4 \%$ compared with the traditional safety factor. (d) shows the tracking state of the actual CVT ratio to the target ratio under the NEDC cycle. Although the actual ratio is greater than the target ratio in several time periods, their difference is not large. In general, the CVT actual ratio optimised by 
the designed controller can track the target well and meet the control needs of the vehicle. (e) compares the CVT secondary pulley pressure based on MPC and safety factor control strategies. Analysis of the results shows that compared with the traditional safety factor control strategy, the secondary pulley pressure optimised by the MPC clamping force controller obtains better value than the safety factor control strategy. The controller can more accurately and reasonably optimise the CVT clamping force.

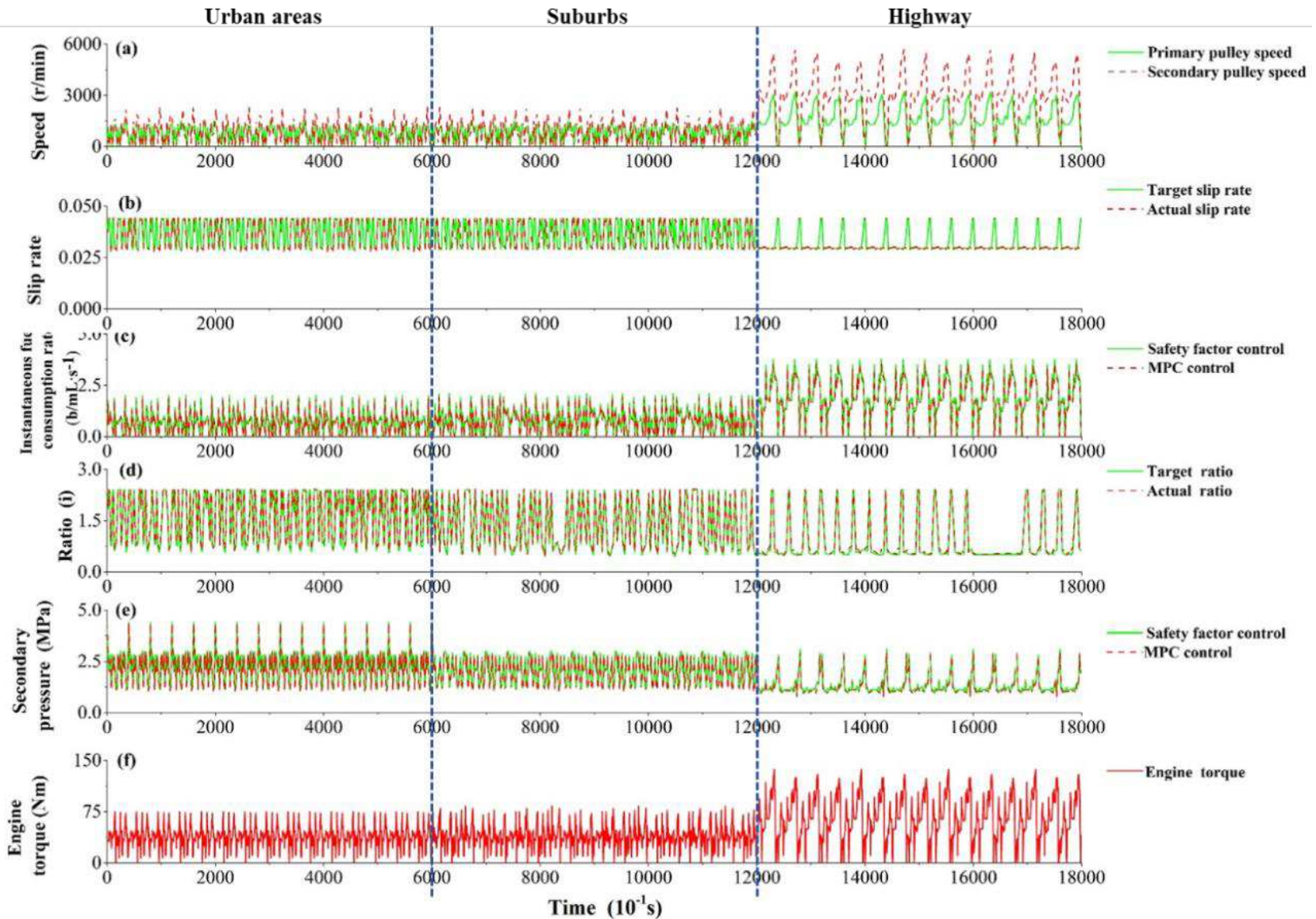

Figure 20 NEDC cycle conditions test (a) primary and secondary pulley speed (b) slip (c) instantaneous fuel consumption rate(d) ratio (e) secondary pulley pressure and (f) engine torque

\section{Drum Test}

The control effect is verified using a full-vehicle drum test under comprehensive conditions. The designed controller is transplanted to the real vehicle for verification (in Figure 21) and the calibration tool CANape is used to collect and record the data. The test platform uses an independent Chinese brand of automotive CVT. Table 2 , Table 3 show the test parameters and the chassis dynamometer parameters, respectively.

Table 2 Test parameters

\begin{tabular}{lr}
\hline Parameter (Unit) & Value \\
\hline Total mass (kg) & 1360 \\
CVT ratio range & $0.46-2.43$ \\
Area ratio of cylinders & 2.012 \\
Engine displacement (L) & 1.498 \\
Pulley centre distance (m) & 0.153 \\
Cone Angle of pulley $\left({ }^{\circ}\right)$ & 11 \\
Oil pump displacement (L) & 9.6 \\
\hline
\end{tabular}

\begin{tabular}{lc}
\hline Metal belt length $(\mathrm{m})$ & 0.818 \\
\hline
\end{tabular}

Table 3 Chassis dynamometer parameters

\begin{tabular}{lr}
\hline Parameter (Unit) & Value \\
\hline Driving form & 4 WD \\
Drum size (feet) & 48 \\
Maximum vehicle speed $(\mathrm{km} / \mathrm{h})$ & 200 \\
Wheelbase adjustment range $(\mathrm{m})$ & $2.1-4.7$ \\
Maximum uniaxial load $(\mathrm{kg})$ & 4500 \\
Inertia simulation range $(\mathrm{kg})$ & $454-5400$ \\
\hline
\end{tabular}




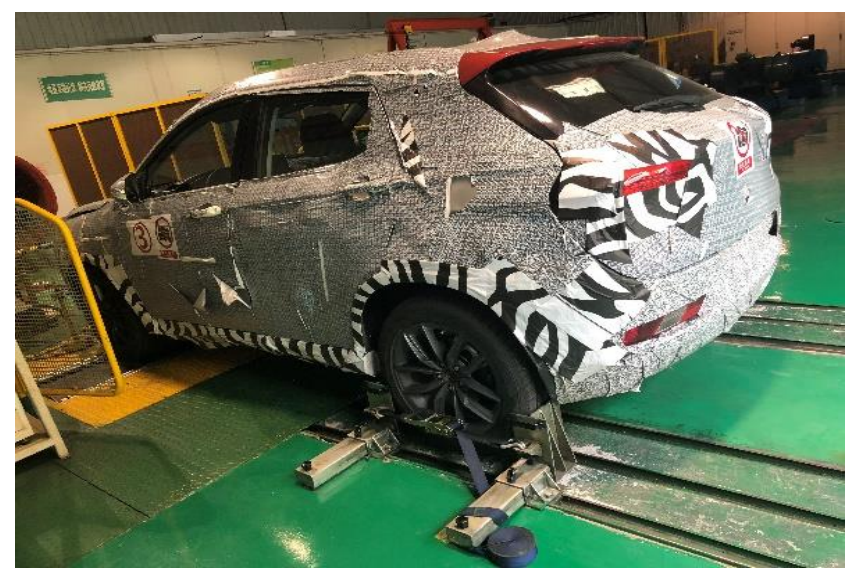

Figure 21 Real vehicle for drum test
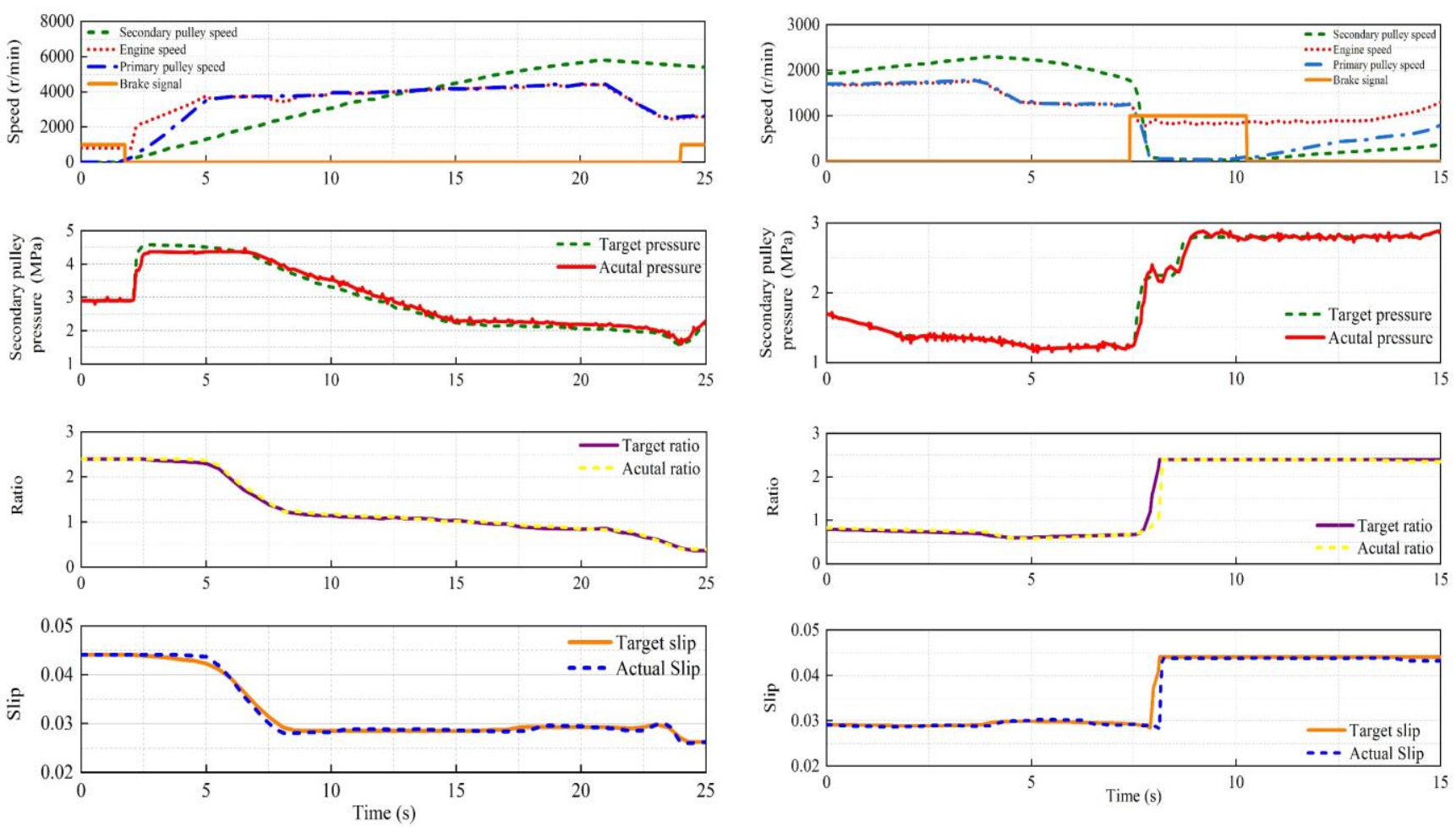

(a)

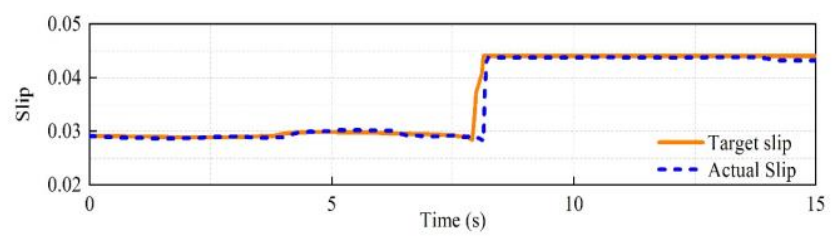

(b) 

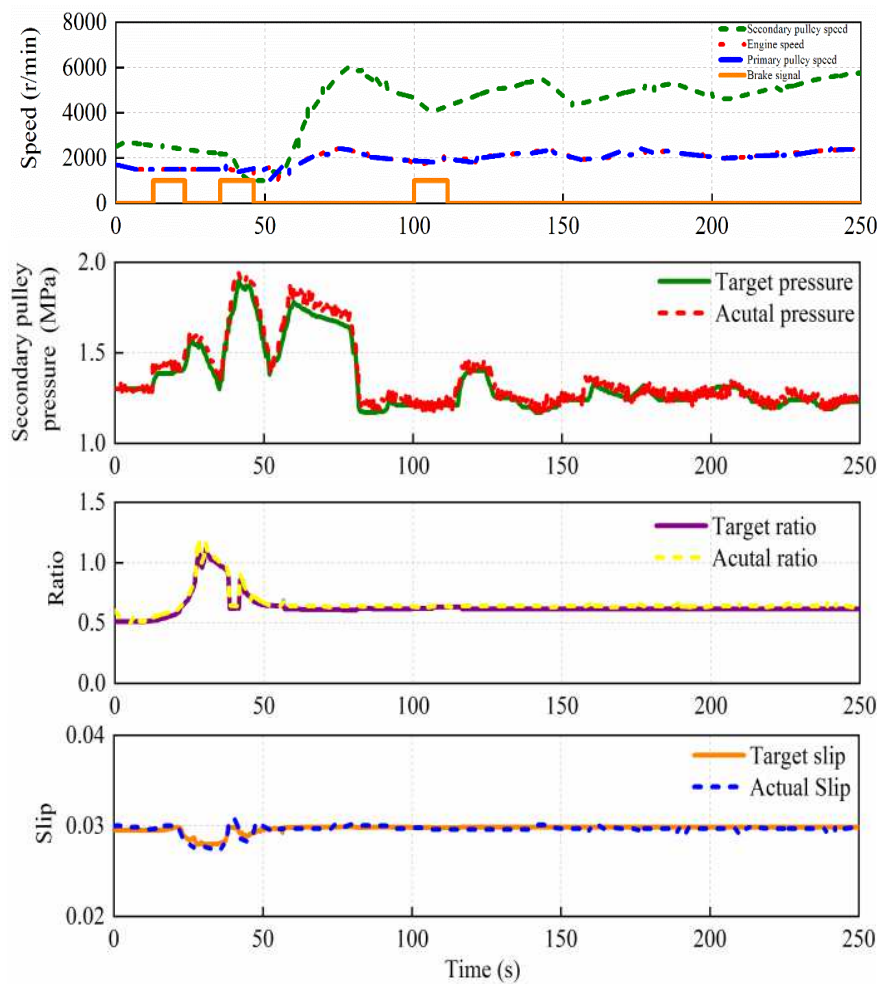

250 the efficiency of the CVT transmission also increases. Compared with traditional safety factor, the efficiency of CVT vehicle based on MPC improves by approximately $9.12 \%-9.35 \%$.
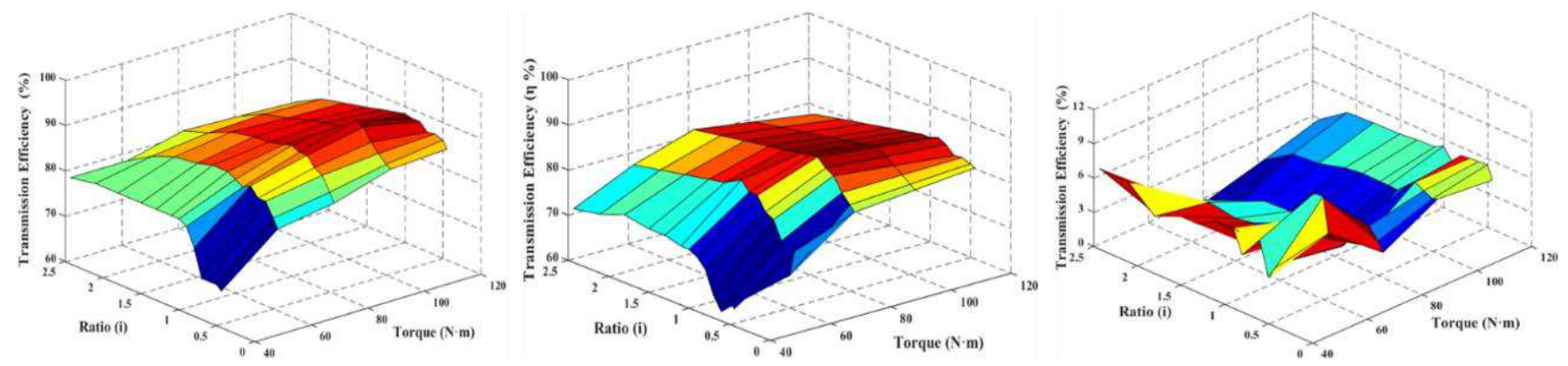

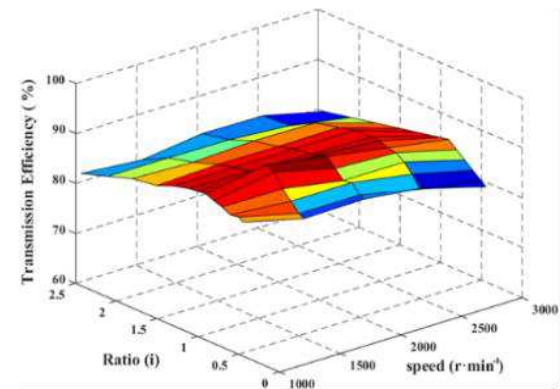

(a)

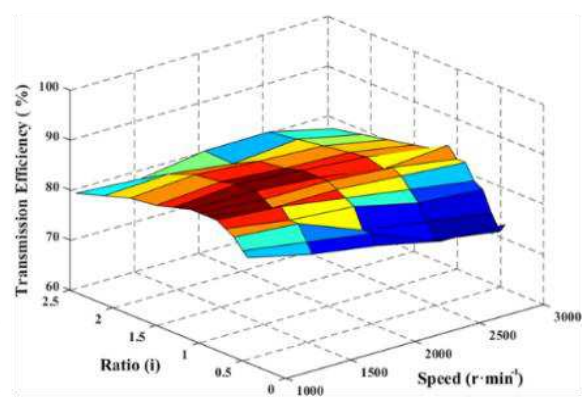

(b)

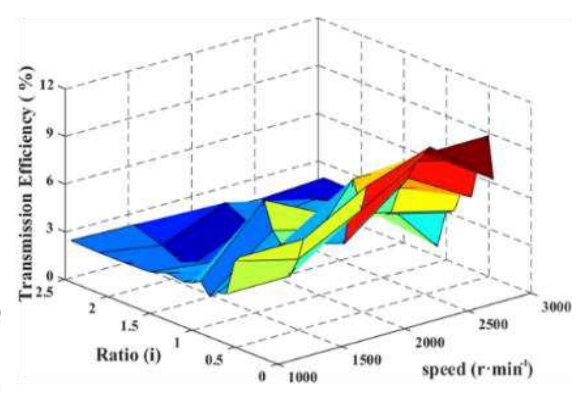

(c)

Figure 23 Comparison of efficiency improvement of CVT (a) Traditional control (b) MPC control (c) efficiency difference

\section{Conclusions}

This study proposes a new integrated optimization control method to meet the CVT expected transmission efficiency range, which conventional control cannot achieve. A new slip state dynamic equation is obtained and the clamping force bench is established. The relationship between the driver intention and the target ratio is obtained to control the actual ratio in real time. Then, a comprehensive optimization control strategy based on engine and transmission is proposed based on driver intention and slip. Finally, the controller is transplanted to the domestic CVT vehicle on the turntable to determine the efficiency under 
comprehensive working conditions. The main findings can be summarised as follows.

(1) The slip characteristics and related constraints are considered and new slip dynamics mathematical model and the clamping force test bench are established. The working characteristics of the engine determine economic working curve of the vehicle.

(2) The input variable accelerator pedal opening and its rate of change are analysed and processed based on fuzzy control strategy to obtain the relationship between the driver intention and the CVT target ratio at the corresponding time.

(3) Firstly, the internal combustion engine torque and slip between the metal belt and pulley are taken as optimization targets. Then, a joint controller based on MPC is designed, which allows the controller to repeatedly solve the optimization in real-time.

(4) The new and tested controller has good robustness and the vehicle performance under NEDC comprehensive condition is verified. Compared with traditional control, the new control method can improve efficiency by approximately $9.12 \%-9.35 \%$.

\section{Declaration}

\section{Acknowledgements \\ Funding}

Supported by National Natural Science Foundation of China (Grant No. 51905044)

\section{Availability of data and materials}

The datasets supporting the conclusions of this article are included within the article.

\section{Authors' contributions}

The author' contributions are as follows: Han Ling was in charge of the whole trial; Liu Hongxiang wrote the manuscript; Zhang Hui and Fang Ruoyu assisted with sampling and laboratory analyses.

\section{Competing interests}

The authors declare no competing financial interests.

\section{Consent for publication}

Not applicable

\section{Ethics approval and consent to participate}

Not applicable

\section{References}

[1] Zeng X H, Wu Z Q, Wang Y, et al. Multi-mode energy management strategy for hydraulic hub-motor auxiliary system based on improved global optimization algorithm. Sci China Tech Sci, 2020, 63, https://doi.org/10.1007/s11431-019-1526-8

[2] Ehsani M, Gao Y, Gay S, et al. Modern Electric, Hybrid Electric, and Fuel Cell Vehicles, Fundamentals, Theory, and Design. 2nd ed. CRC Press LLC, 2010.

[3] Sciarretta A, de Nunzio G, Ojeda L L. Optimal ecodriving control: energy-efficient driving of road vehicles as an optimal control problem. IEEE Control Syst, 2015, 35: 71-90

[4] Eiji Tsuchiya, Eiji Shamoto. Formulation of intervibrator motion and development of a controller for a pulse-drive transmission. Mechanism and Machine Theory 2020; 150, 103880.

[5] Chih-Hong Lin. Novel application of continuously variable transmission system using composite recurrent Laguerre orthogonal polynomials modified PSO NN control system. ISA Transactions 64 (2016) 405-417.

[6] KHANIKI H B, ZOHOOR H, SOHRABPOUR S. Performance analysis and geometry optimization of metal belt -based continuously variable transmission systems using multi-objective particle swarm optimization. Journal of the Brazilian Society of Mechanical Sciences \& Engineering, 2017, 39 (3): 1-15.

[7] Eiji Tsuchiya, Eiji Shamoto. Formulation of intervibrator motion and development of a controller for a pulse-drive transmission. Mechanism and Machine Theory150 (2020) 103880.

[8] Daohai Qu, Wei Luo, Yunfeng Liu, et al. Simulation and experimental study on the pump efficiency improvement of continuously variable transmission. Mechanism and Machine Theory 2019; 131, 137-151.

[9] Ren, Xiang; Li, Dawei; Qu, Ronghai; et al. Back EMF Harmonic Analysis of Permanent Magnet Magnetic Geared Machine. IEEE Transactions on Industrial Electronics 2020; 67(8): 6248-6258.

[10] MEULEN S V D, JAGER B D, VELDPAUS F, et al. Combining extremum seeking control and tracking control for high-performance CVT operation. Control Engineering Practice, 2014, 29: 86-102.

[11] He G Z, Xie H, He S J. Overall efficiency optimization of controllable mechanical turbo-compounding system for heavy duty diesel engines. Sci China Tech Sci, 2017, 60: 36-50, doi: 10.1007/s11431-015-0754-6.

[12] F X Liu, W Wu, J B Hu, et al. Design of multi-range hydro-mechanical transmission using modular method. Mechanical Systems and Signal Processing 126 (2019) 1-20.

[13] KOBAYASHI D, MABUCHI Y, KATOH Y. A study on the torque capacity of a metal pushing v-belt for CVTs // Society of Automotive Engineers Transmission and Driveline Systems Symposium. Detroit: SAE, 1998:980822.

[14] BONSEN B, KLAAMSSEN T, MEERAKKER K, et al. Analysis of slip in a continuously variable transmission //American Society of Mechanical Engineers. International Mechanical Engineering Congress and Exposition, Dynamic Systems and Control November 15-21, 2003, Washington DC, USA: ASME, 2003: 995-1000.

[15] Yu-Long Lei, Yu-Zhe Jia, Yan Fu, et al. Car Fuel Economy Simulation Forecast Method Based on CVT Efciencies Measured from Bench Test, Chin. J. Mech. Eng. (2018) 31:83.

[16] HIROYUKI N, HIROYUKI Y, HIDEYUKI S, et al. Friction characteristics analysis for clamping force setup in metal V-belt type CVT. 2005 SAE Congress. Detroit, USA, 2005-01-1462. 
[17] AKEHURST S, VAUGHAN N D, PARKER D A, et al. Modeling of loss mechanisms in a pushing metal v-belt continuously variable transmission. Part 2: deflection losses and total torque loss validation. Proc IMechE Part D: Journal of Automobile Engineering, 2004,218(11):1295-1306.

[18] NARITA K, PRIEST M. Metal-mental friction characteristics and the transmission efficiency of a metal V-belt-type continuously variable transmission. Proc IMechE Part J: Engineering Tribology, 2007,221:11-26.

[19] Ruan, J.; Walker, P.; Zhang, N. A comparative study energy consumption and costs of battery electric vehicle transmissions. Appl. Energy 2016, 165, 119-134.

[20] Kim W, Vachtsevanos G. Fuzzy logic ratio control for a CVT hydraulic module. In Proceeding of IEEE symposium on intelligent control, 2000, p. 151-156.

[21] Antti Ritari, Jari Vepsäläinen , Klaus Kivekäs, et al. Energy Consumption and Lifecycle Cost Analysis of Electric City Buses

[27] vertical vibration. Sci China Tech Sci, 2017, 60: 1732-1746, doi: 10.1007/s11431-017-9091-9.

[28] María F.Villa-Tamayob, Michelle A. Caicedob, Pablo S. Rivadeneiraa. Offset-free MPC strategy for nonzero regulation of linear impulsive systems. ISA Transactions 101 (2020) 91-101.

[29] Korda M, Mezić I. Linear predictors for nonlinear dynamical systems: Koopman operator meets model predictive control. Automatica 2018; 93:149-160.

[30] Real-time fuel economy optimization with nonlinear mpc for phevs. IEEE Trans Control Syst Tech, 2016, 24: 1-9.

[31] Ke Shi, Dong Cheng, Xiaofang Yuan, et al. Interacting multiple model-based adaptive control system for stable steering of distributed driver electric vehicle under various road excitations. ISA Transactions, 103 (2020) 37-51.

[32] Song Z F, Xia C L, Liu T, et al. A modified predictive control strategy of three-phase grid-connected converters with optimized action time sequence. Sci China Tech Sci, 2013, 56: 1017-1028.

[33] Guo L, Gao B, Li Y, etal. A fast algorithm for nonlinear model predictive control applied to HEV energy management systems. Sci China Inf Sci, 2017, 60: 092201.

[34] Beuerle, S., Optimization Methodology for CVT Ratio Scheduling with Consideration of Both Engine and CVT Efficiency, Master's Thesis, Western Michigan University, 2016. with Multispeed Gearboxes. Energies 2020, 13, 2117

[22] PICK D F, WANG D-Y D, PROCTOR R W, et al. Dead pedal and the perception of performance of a continuously variable transmission // Proceedings of SAE 2005 World Congress and Exhibition. Detroit: SAE, 2005.

[23] Zhao J H, Zhou S T, Hu Y F, et al. Open-source dataset for control-oriented modelling in diesel engines. Sci China Inf Sci, 2019, 62(7): 077201, https://doi.org/10.1007/s11432-018-9783-x

[24] Kim, S , Sim, J , Park, J, et al. Elastomeric Continuously Variable Transmission Combined With Twisted String Actuator. IEEE ROBOTICS AND AUTOMATION LETTERS, 2020, 5 (4), 5477-5484.

[25] Qin K J, Wang E H, Zhao H, et al. Development and experimental validation of a novel hybrid powertrain with dual planetary gear sets for transit bus applications. Sci China Tech Sci,2015,58: 2085-2096.

[26] Qian L J, Qiu L H, Chen P, etal. Fuel efficient model predictive control strategies for a group of connected vehicles in corporating

\section{Biographical notes}

Ling Han, born in 1984, is currently an associate professor at Changchun University of Technology, China. She received her $\mathrm{PhD}$ degree from Jilin Universtiy, China, in 2015. Her research interests include mechachonics engineering, machine transmission system.

E-mail: hanling@ccut.edu.cn

Hui Zhang, born in 1995, is currently a master at Changchun University of Technology, China. He received his master degree on mechatronides in Changchun University of Technology, China, in 2018 .

RuoYu Fang, born in 1995, is currently a master at Changchun University of Technology, China. He received his master degree on mechatronides in Jilin University, China, in 2018.

HongXiang Liu born in 1995, is currently a master at Changchun University of Technology, China. He received his master degree on mechatronides in Changchun University of Technology, China, in 2019. 


\section{Appendix}

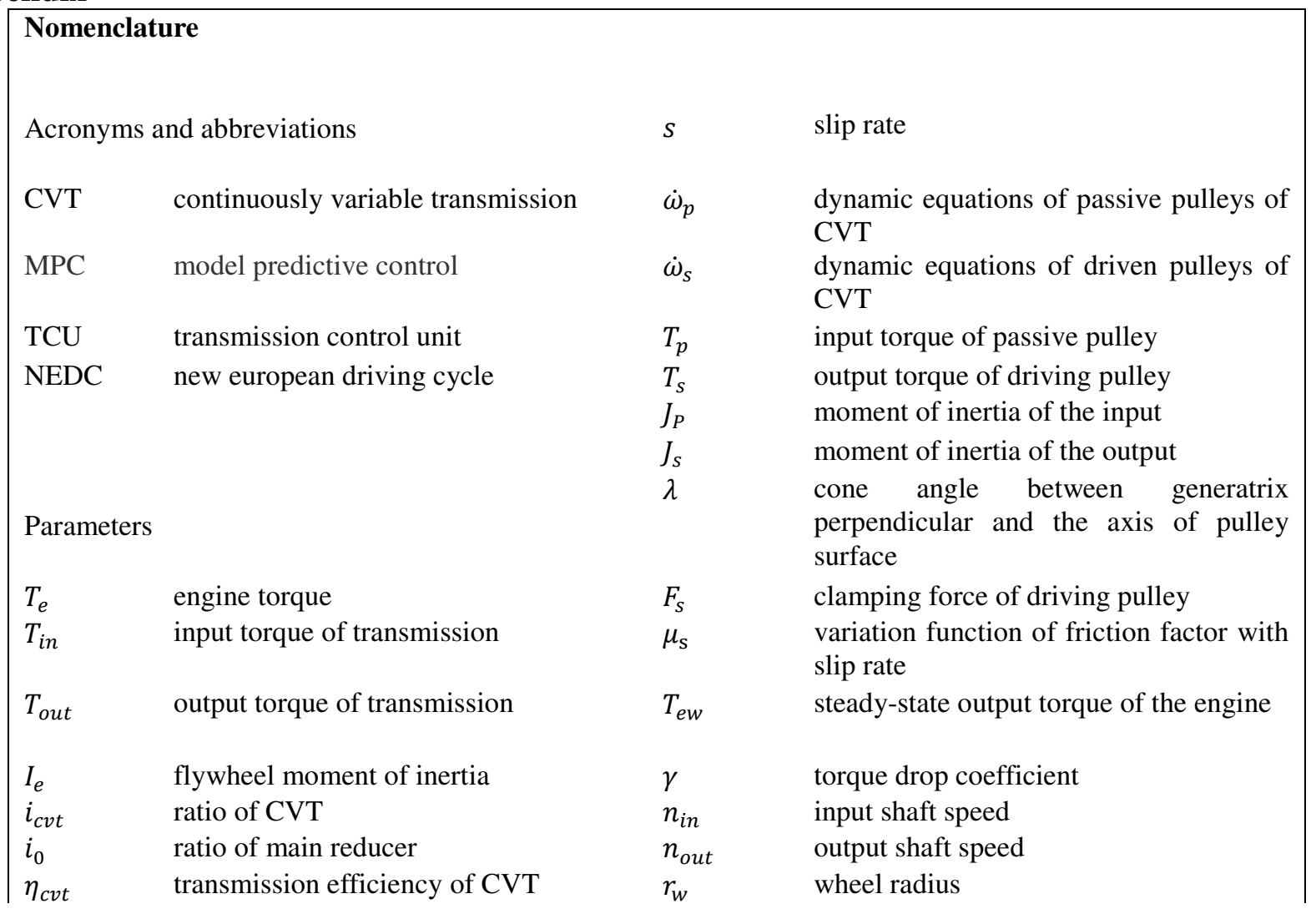




\begin{tabular}{|c|c|c|c|}
\hline$\eta_{0}$ & $\begin{array}{l}\text { transmission efficiency of main } \\
\text { reducer }\end{array}$ & $n_{e}$ & engine speed \\
\hline$T_{r}$ & driven shaft & $v$ & driving speed \\
\hline$T_{d}$ & drive torque of wheels & $n_{m e}$ & target ratio of engine in standard mode \\
\hline$I_{v}$ & $\begin{array}{l}\text { equivalent moment of inertia of the } \\
\text { output shaft }\end{array}$ & $n_{s e}$ & target ratio of engine in dynamic mode \\
\hline$\omega_{v}$ & wheel angular velocity. & $n_{e e}$ & target ratio of engine in economic mode \\
\hline$\omega_{e}$ & $\begin{array}{l}\text { angular velocity of the engine } \\
\text { crankshaft }\end{array}$ & $k$ & $\begin{array}{l}\text { intent parameter of driving set between } \\
0-1 \text { to change continuously }\end{array}$ \\
\hline$\dot{\omega}_{e}$ & engine crankshaft angular acceleration & $\theta$ & accelerator pedal opening \\
\hline$i$ & actual speed ratio of CVT & $\mu(s)$ & linearized friction coefficient \\
\hline$i_{g}$ & theoretical speed ratio of CVT & $\Gamma_{y}$ & error weight coefficient \\
\hline$R_{p}$ & radius of passive pulley & $\Gamma_{u}$ & control weight coefficient \\
\hline$R_{s}$ & radius of driving pulley & $J_{1}$ & $\begin{array}{l}\text { square weighted value of the difference } \\
\text { between the actual measured slip rate in } \\
\text { the predicted time domain and the } \\
\text { reference input }\end{array}$ \\
\hline$\omega_{s}$ & angular velocity of driving pulley & $J_{2}$ & $\begin{array}{l}\text { square-weighted value of the amount of } \\
\text { clamping force change in the control } \\
\text { time domain }\end{array}$ \\
\hline$\omega_{p}$ & angular velocity of primary pulley & & \\
\hline
\end{tabular}


Figures

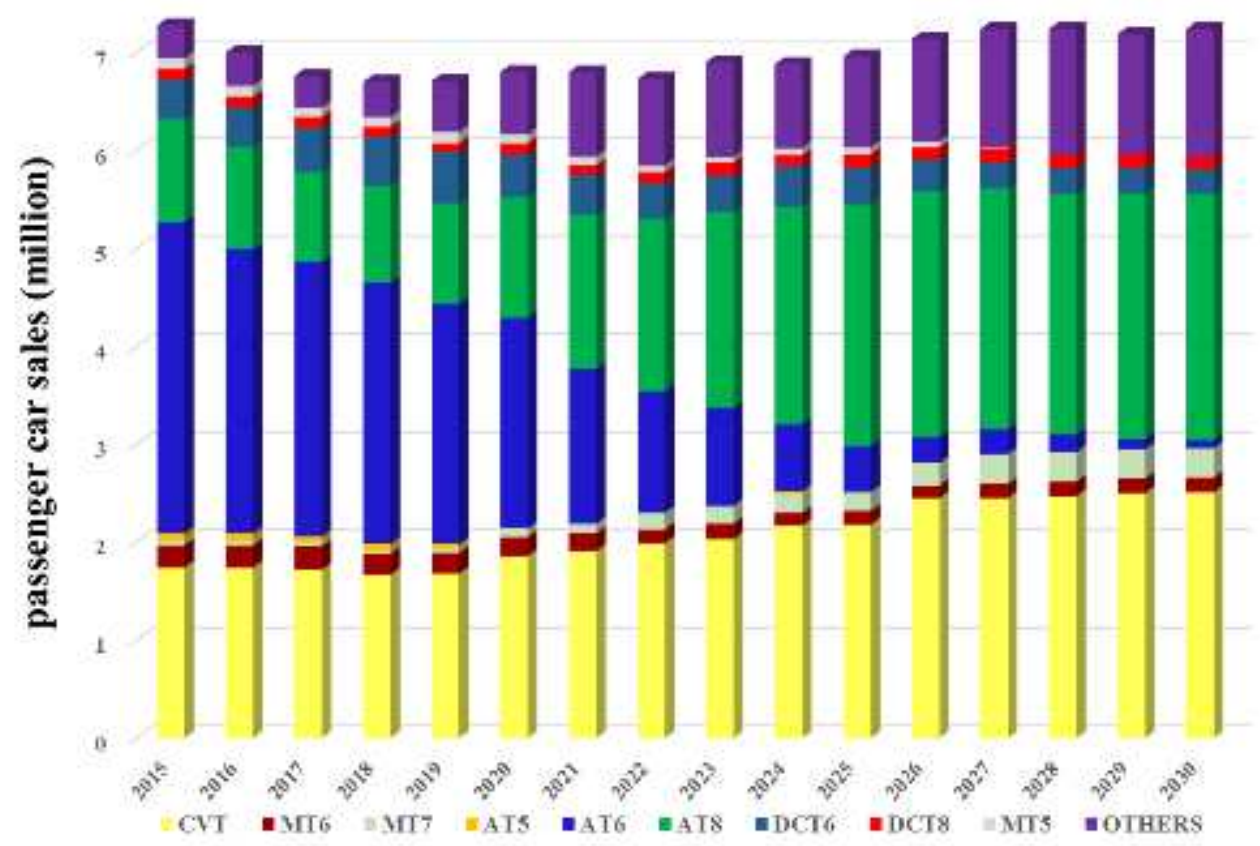

Figure 1

Total production of CVT worldwide from 2015 to 2030

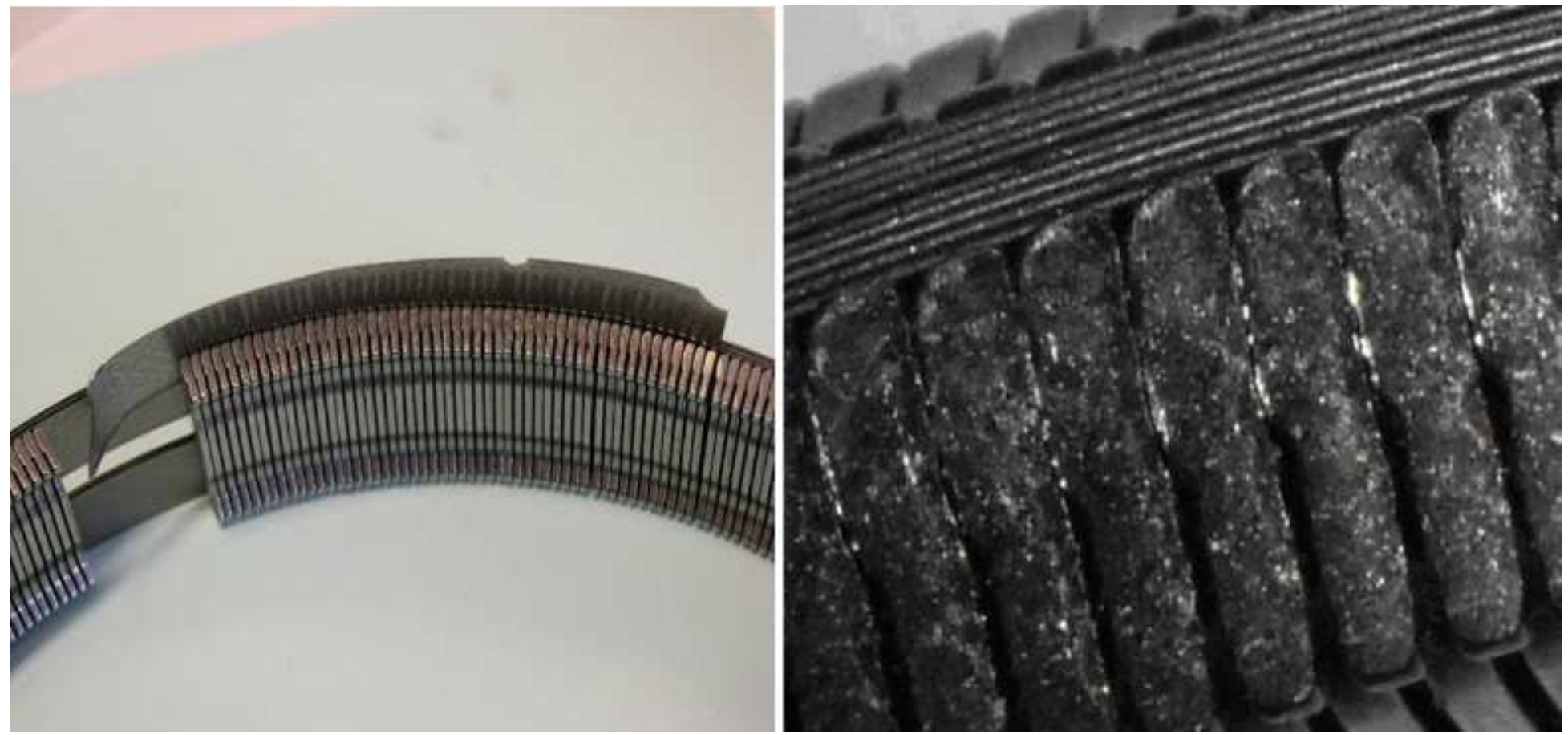

Figure 2

Failure of metal belt and metal sheet 


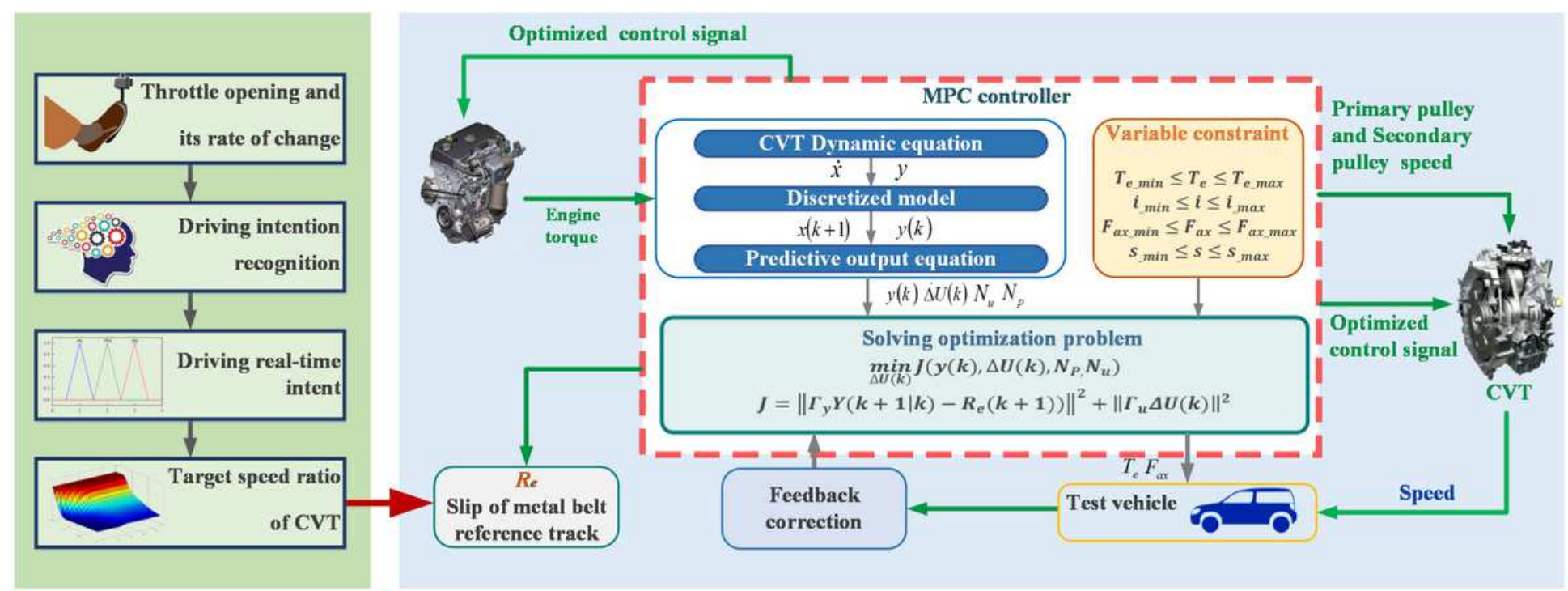

Figure 3

The diagram of overall control strategy

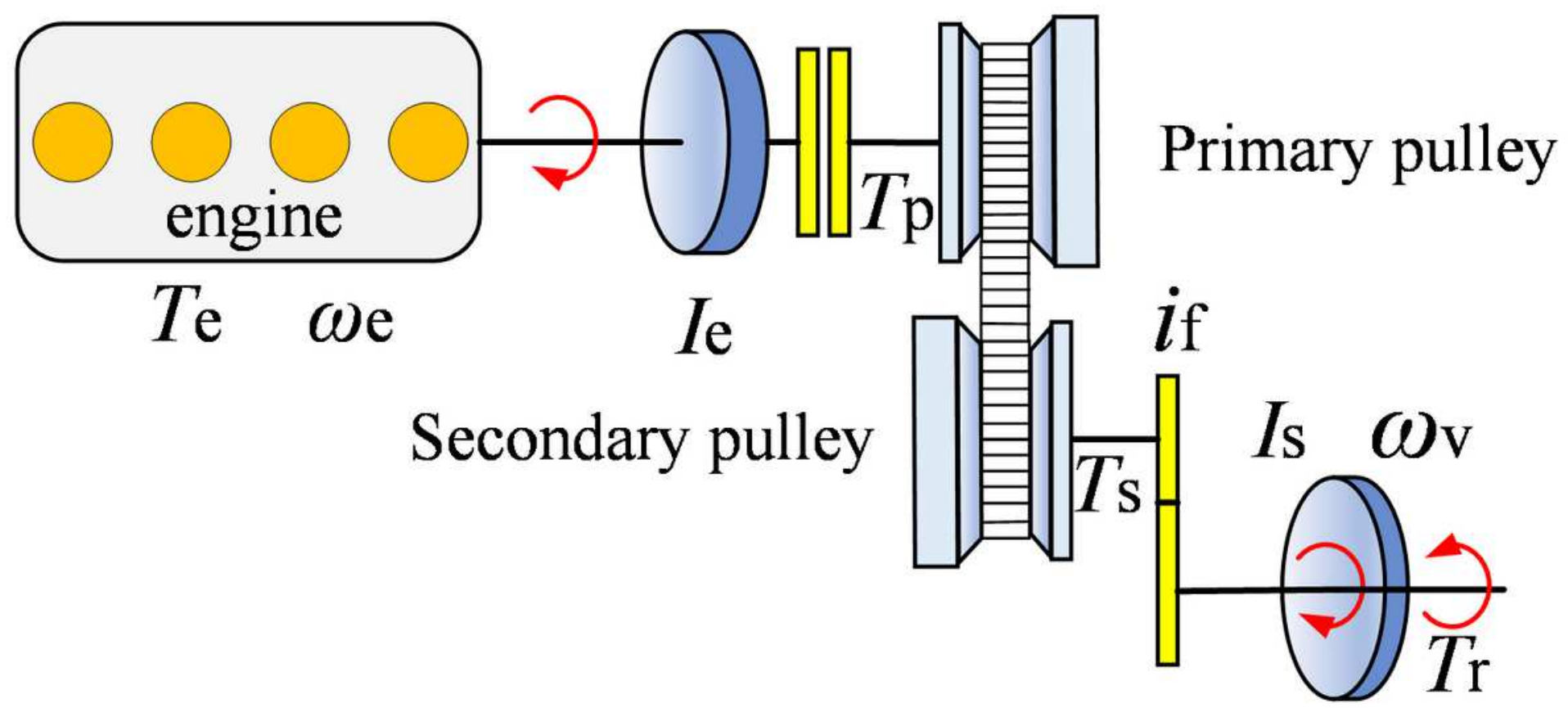

Figure 4

Transmission of CVT system 


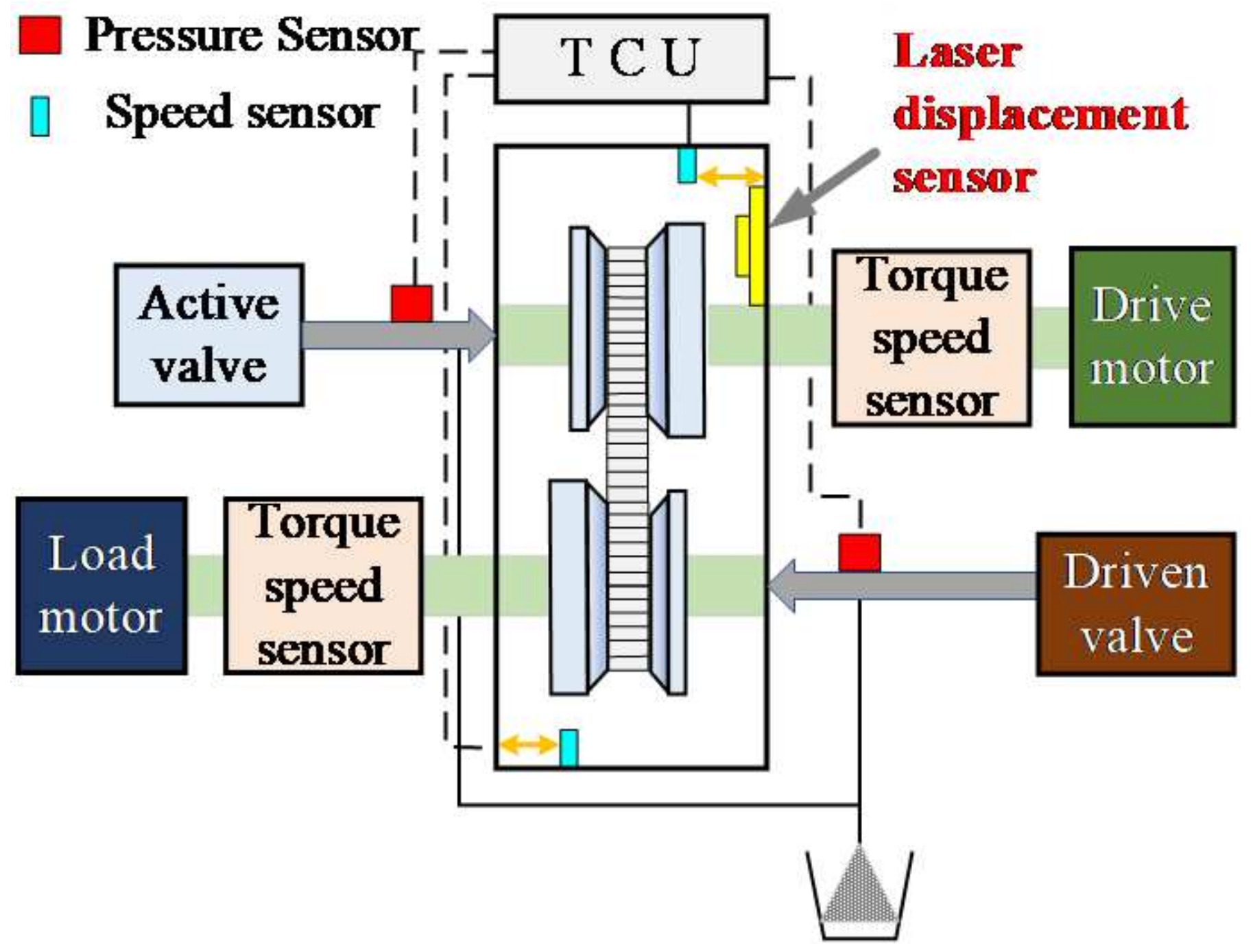

Figure 5

Diagram of clamping force bench test

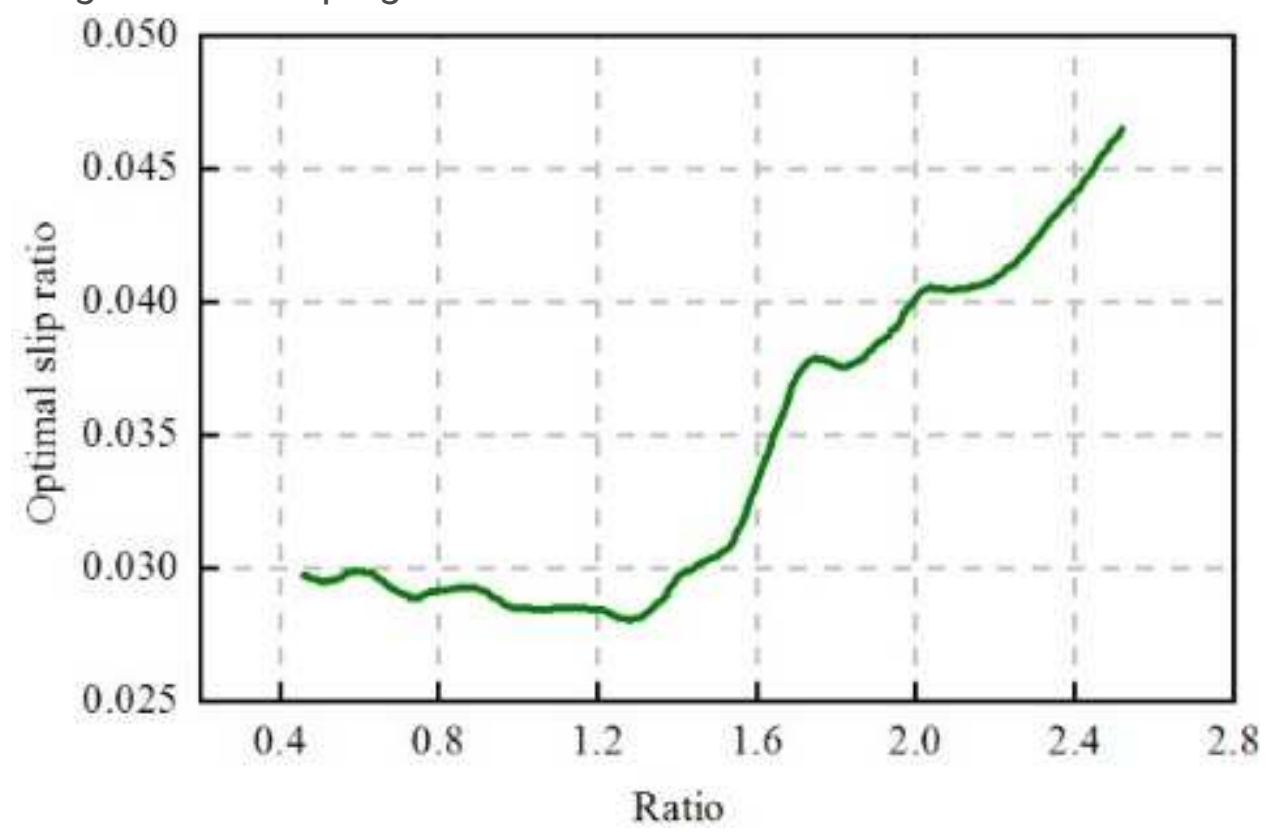


Figure 6

Relationship between optimal slip and ratio

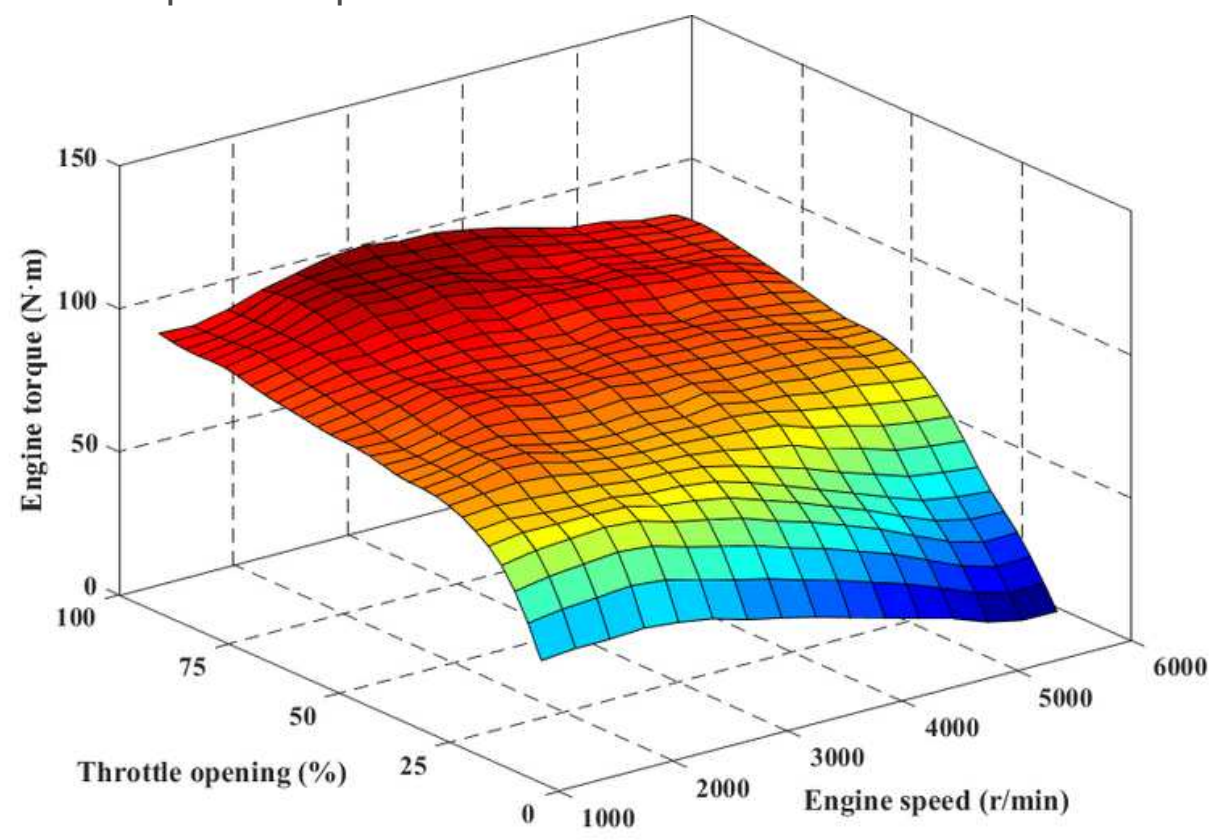

Figure 7

Steady-state engine fuel consumption map

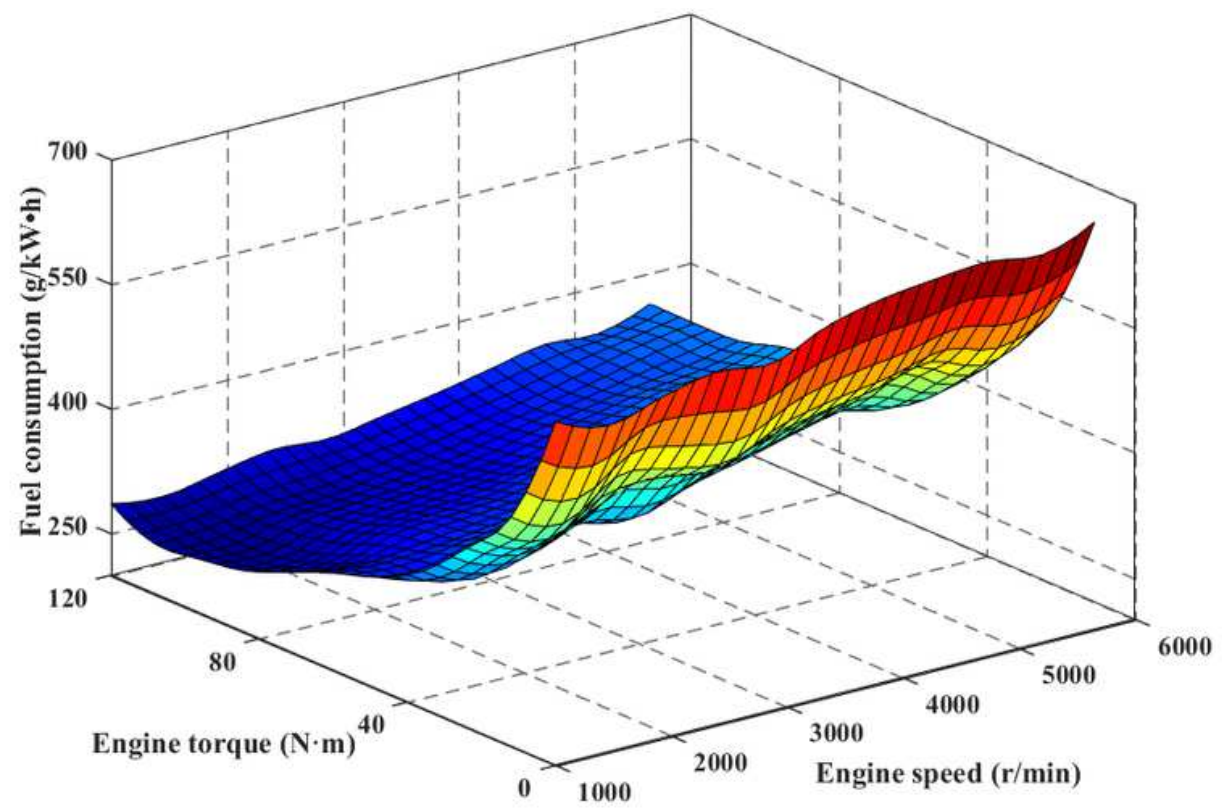

Figure 8

Engine output torque model 


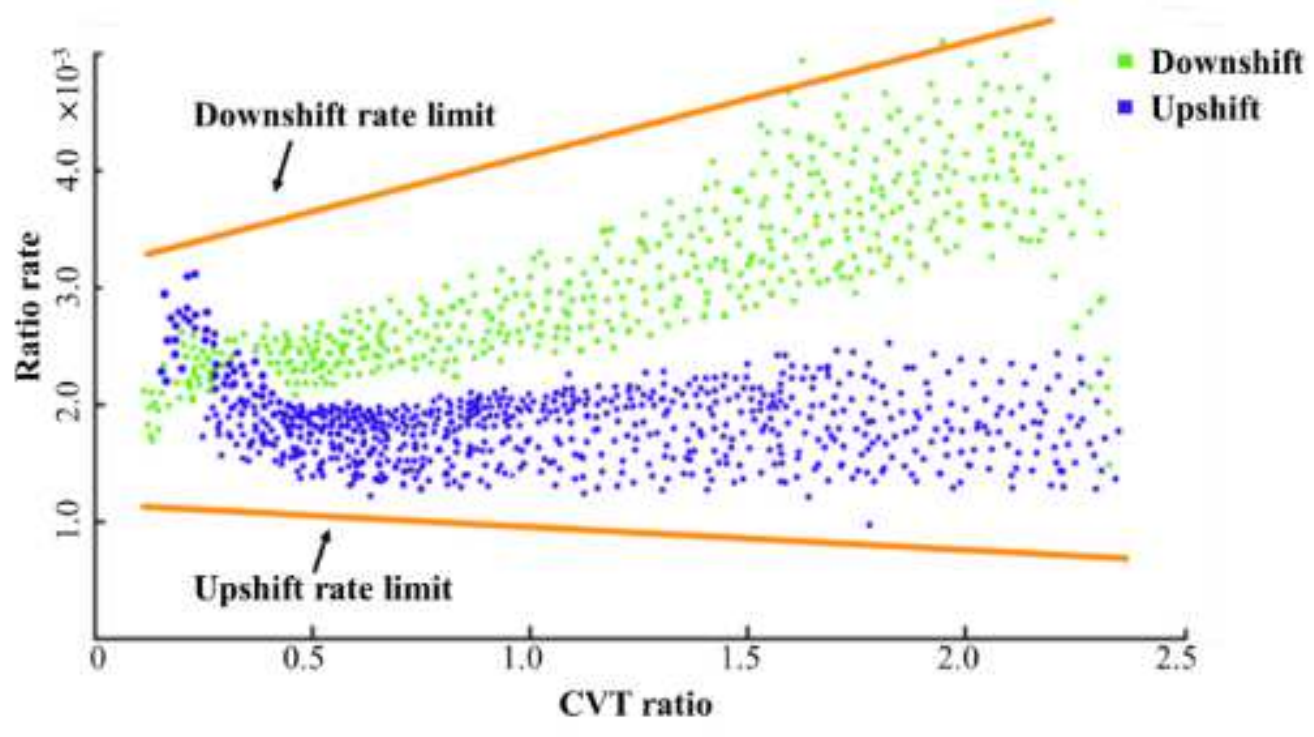

Figure 9

Shift rate limits of CVT ratio

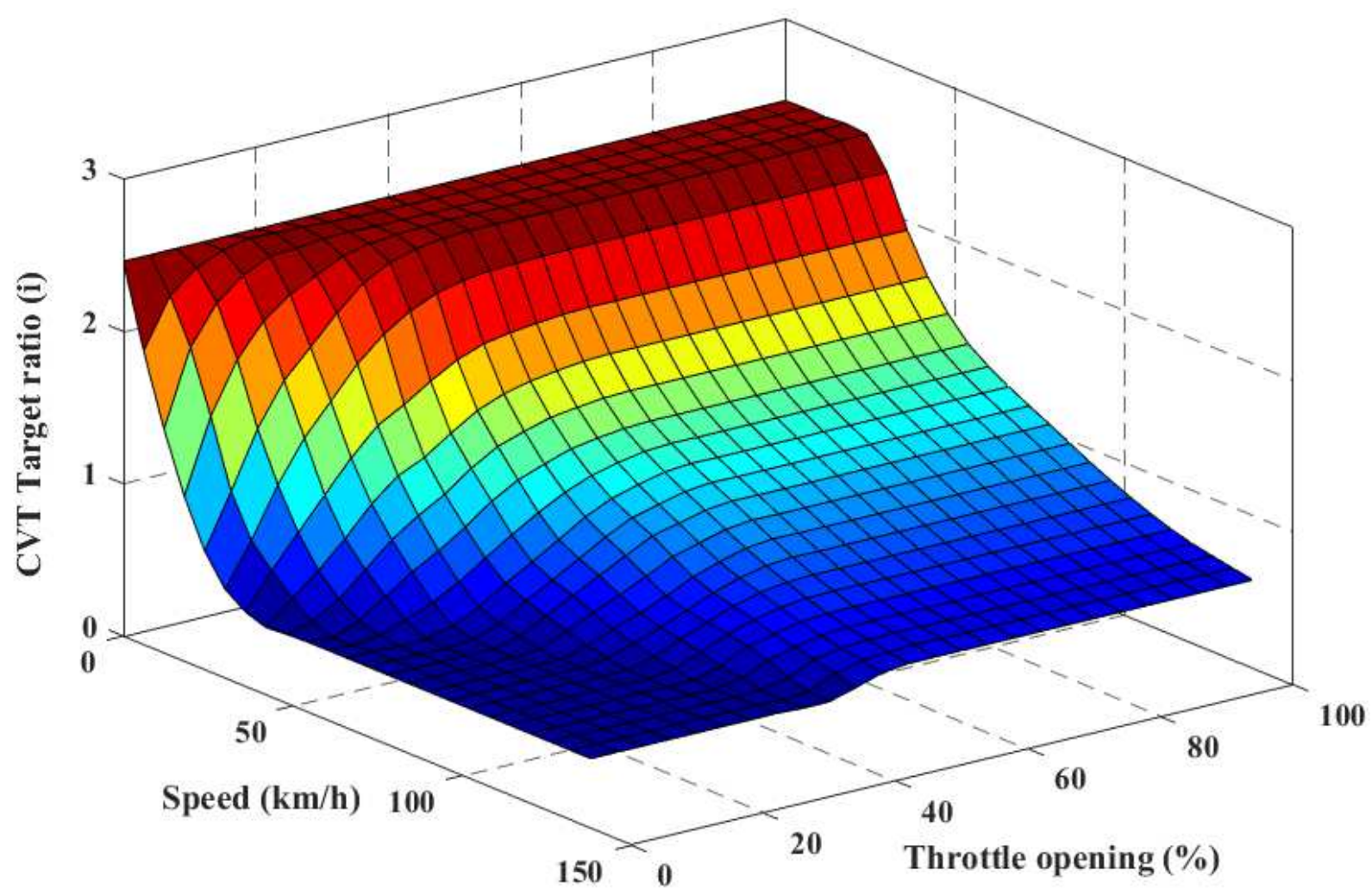

Figure 10

$3 \mathrm{D}$ representation of the best economy of target ratio 


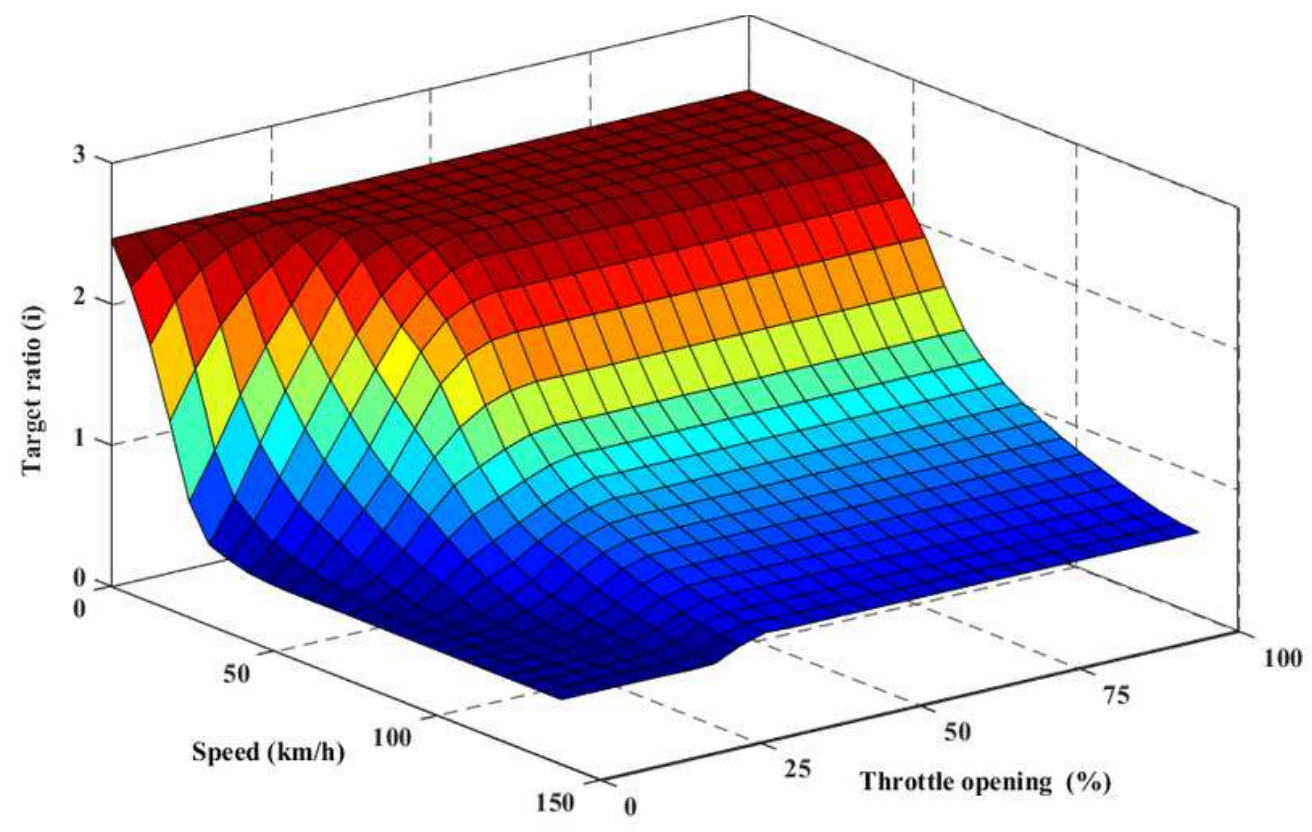

Figure 11

3Drepresentation of the best dynamic of target ratio

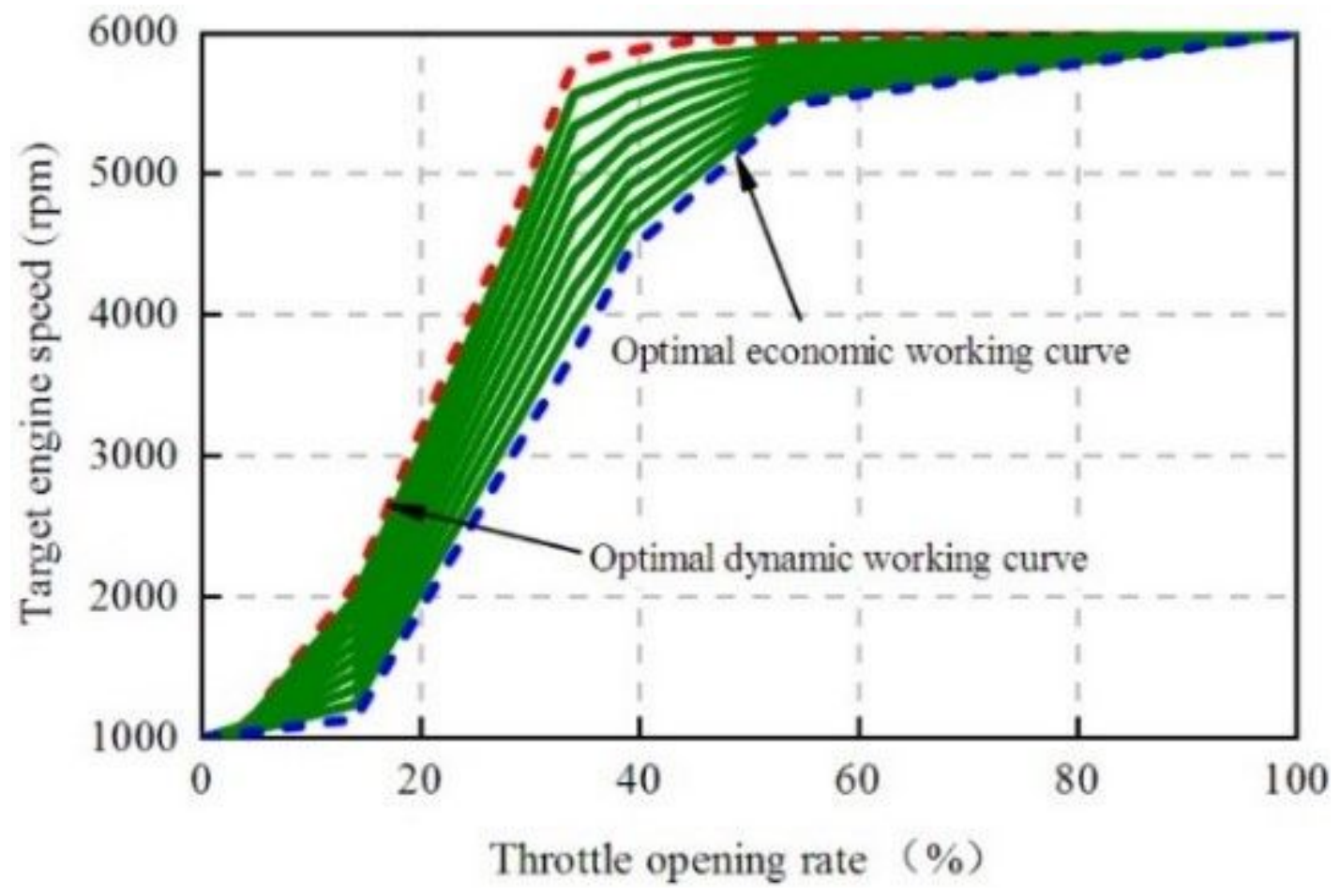

Figure 12

Engine speed regulation characteristic 


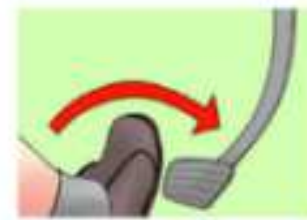

Accelerator pedal open

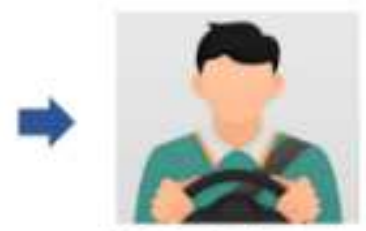

Driver's intent

$$
\begin{array}{cl}
\text { Slow acceleration } & \boldsymbol{K}=0 \\
\text { General acceleration } & 0<\boldsymbol{K}<1 \\
\text { Acceleration } & \mathbf{K}=1
\end{array}
$$

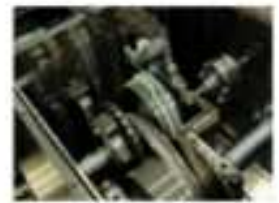

Slip rate output

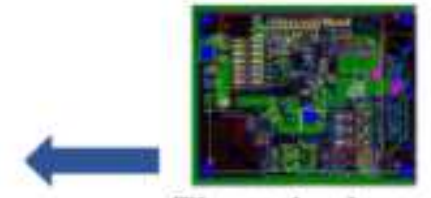

The optimal speed ratio and slip rate

\section{Figure 13}

Driver intent

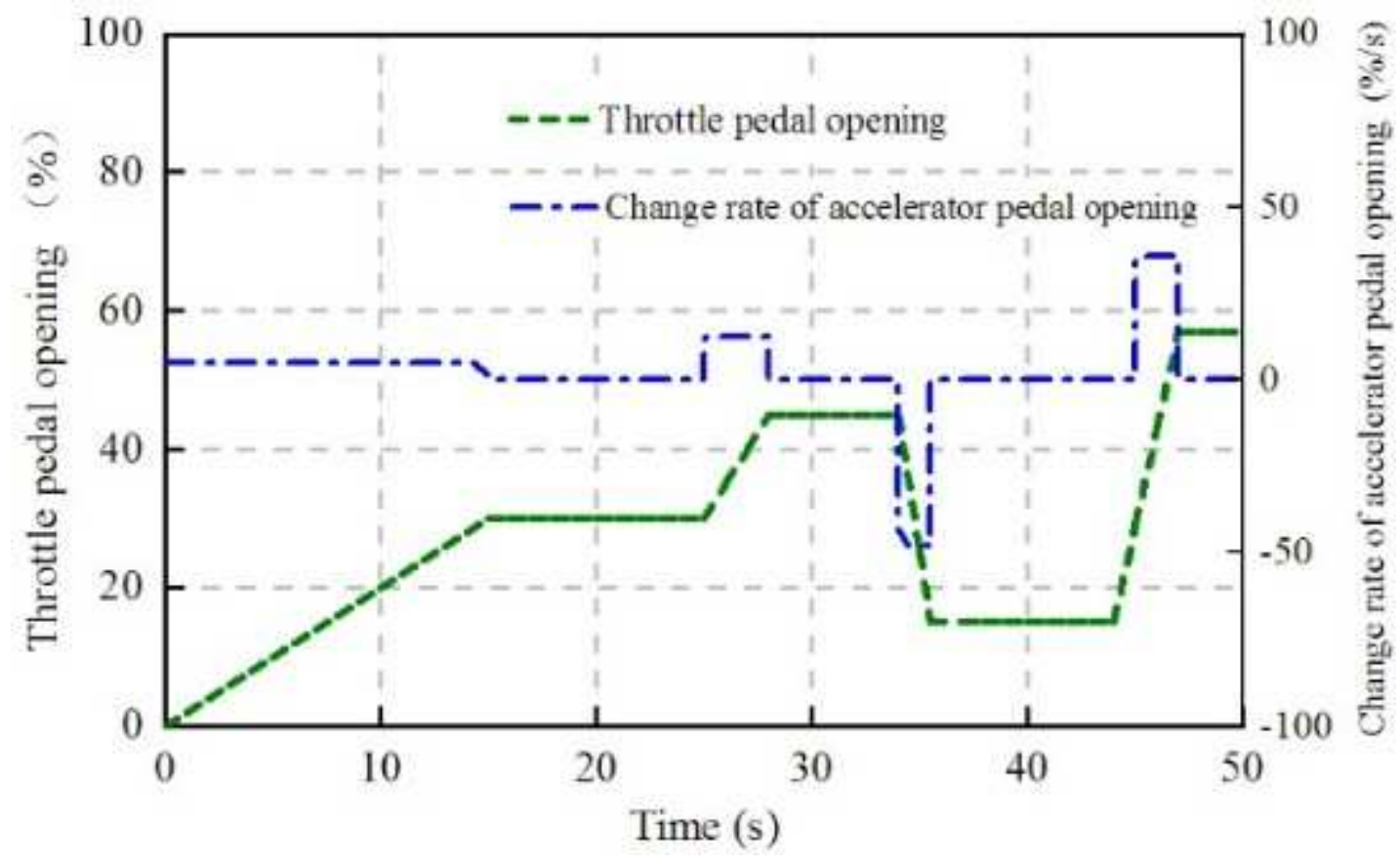

Figure 14

Curve of the accelerator pedal opening and its change rate 


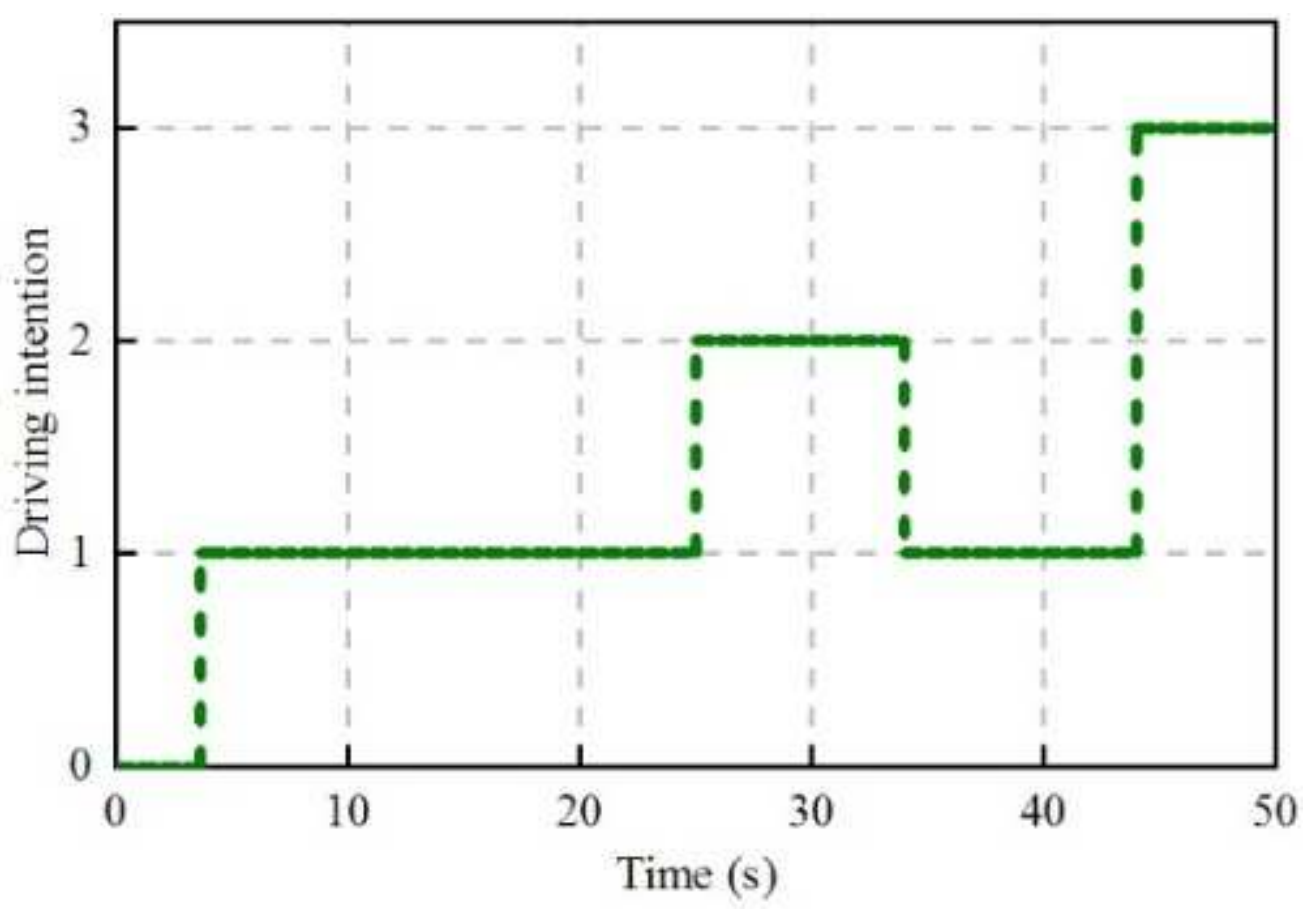

Figure 15

Result of driving intention recognition

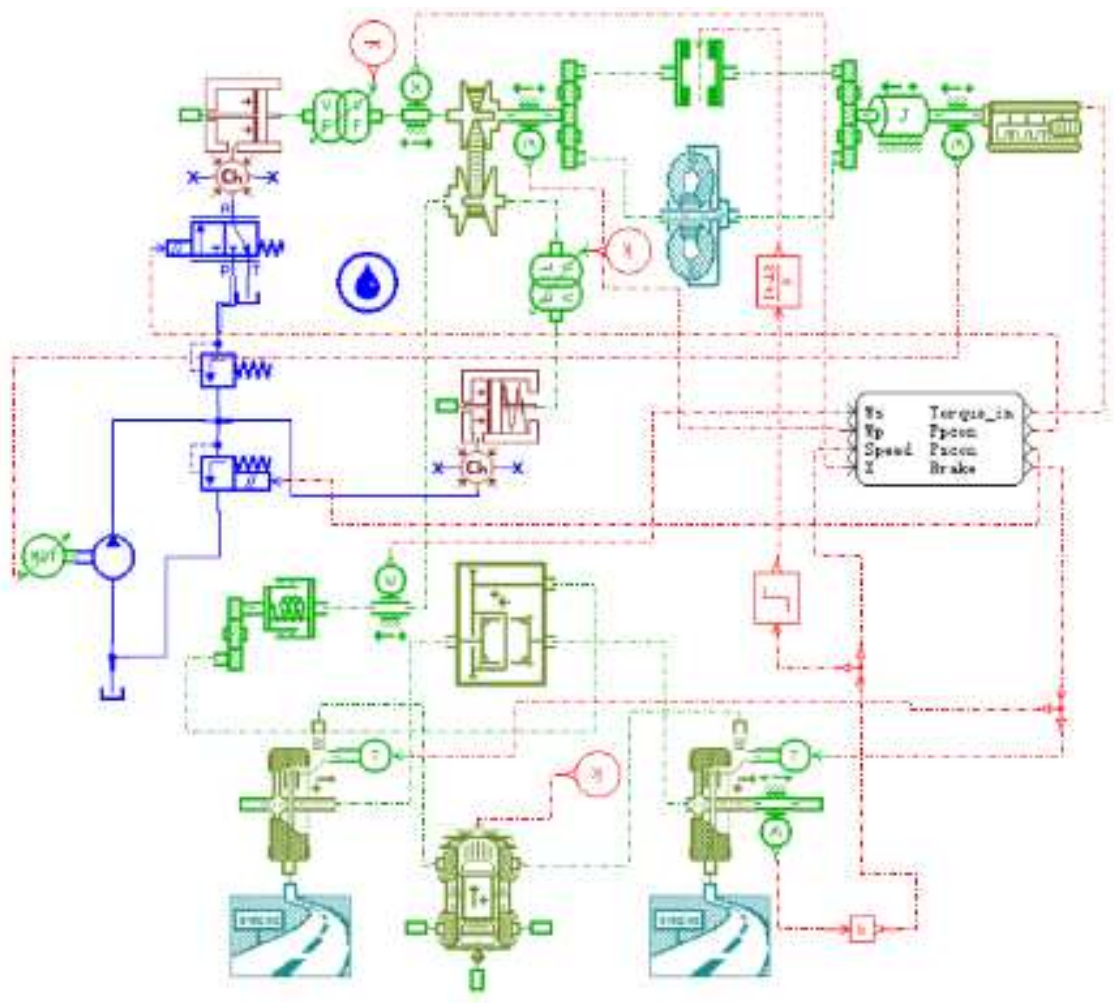

Figure 16

Controller simulation in AMESim 


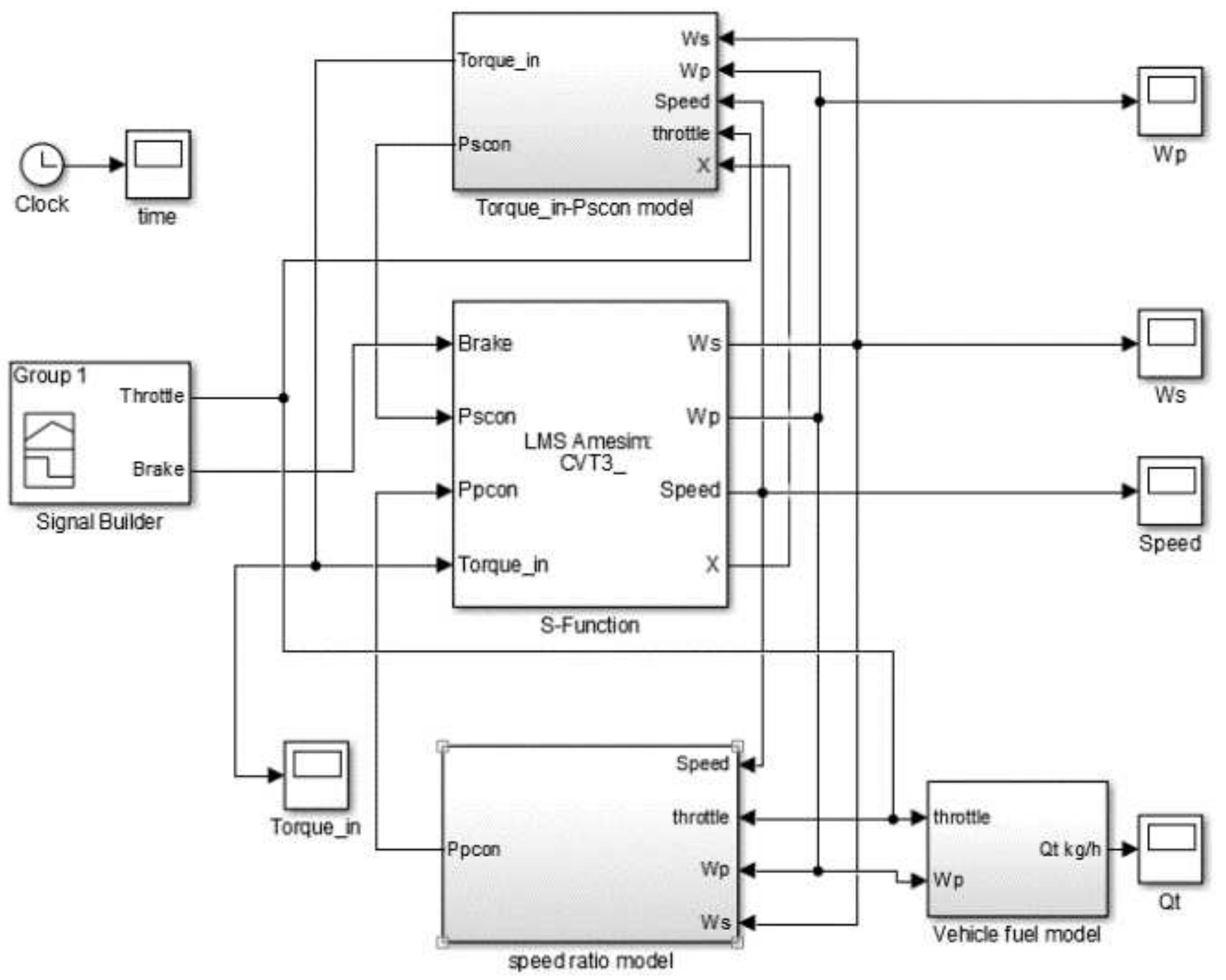

Figure 17

Controller simulation in MATLAB/SIMULINK 

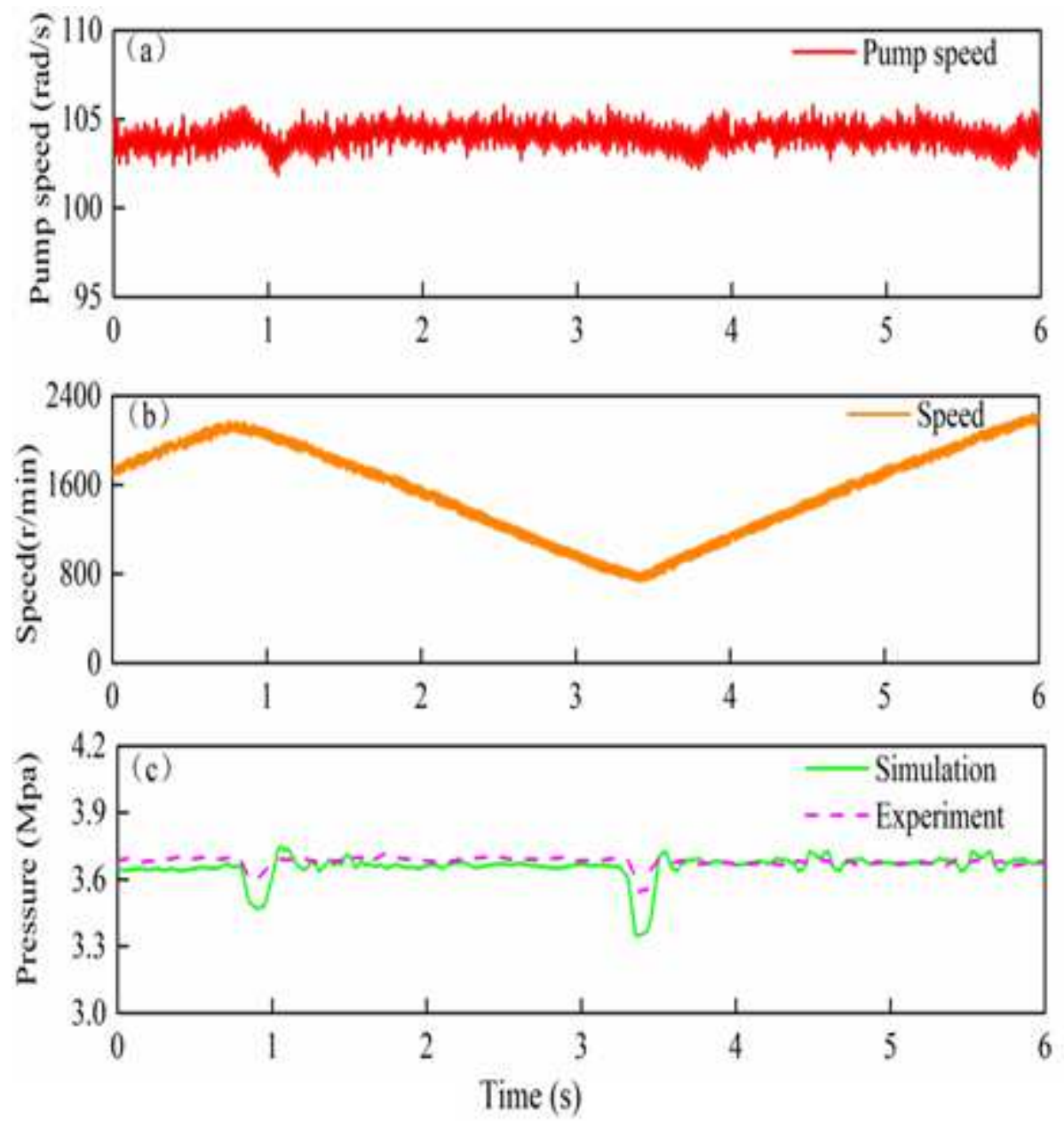

Figure 18

(a) Pump speed (b) Speed (c) Pressure 

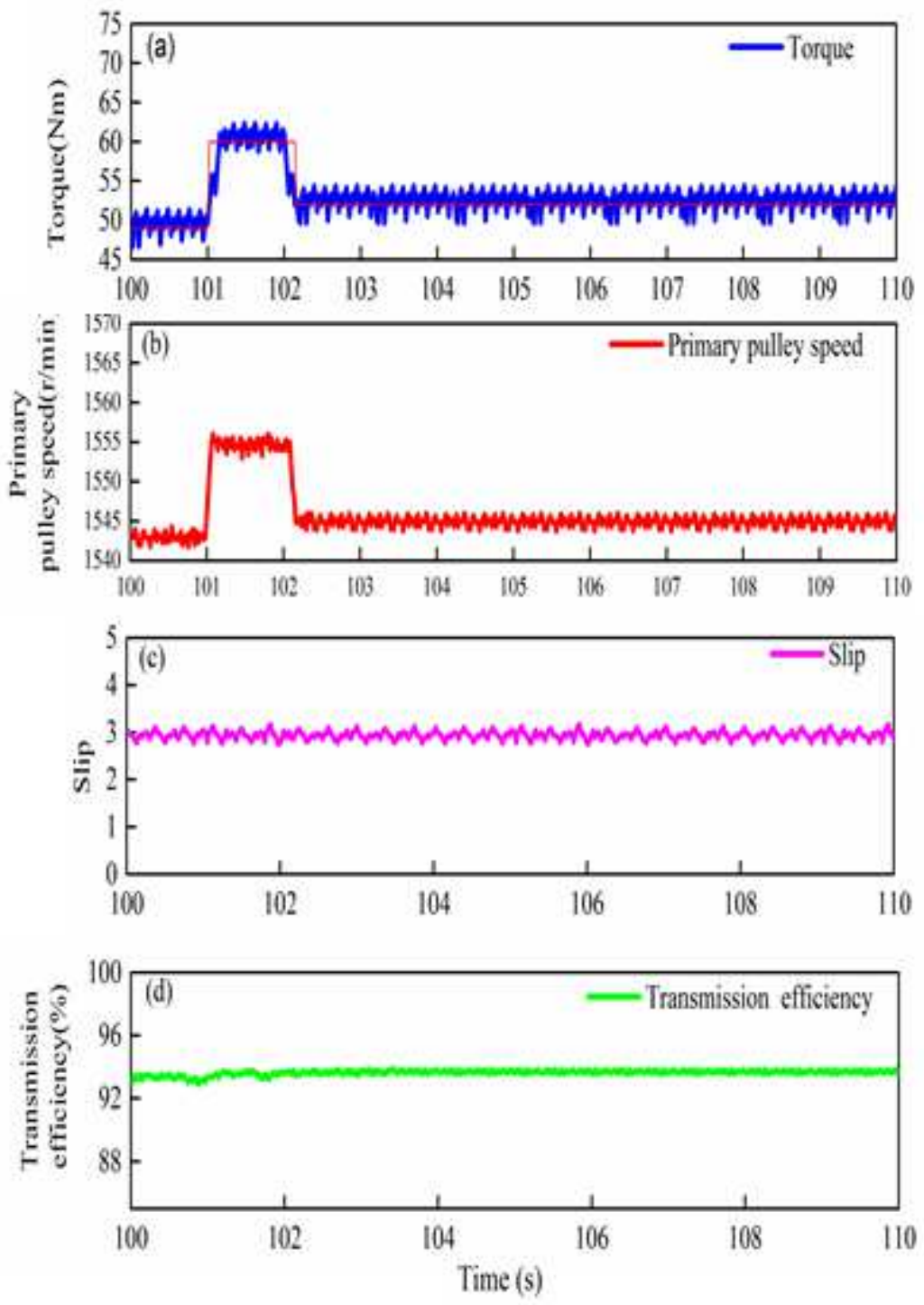

Figure 19

(a) Input side torque step interference (b) Speed of primary pulley (c) Slip (d) CVT transmission efficiency 
Urban areas

Suburbs

Highway

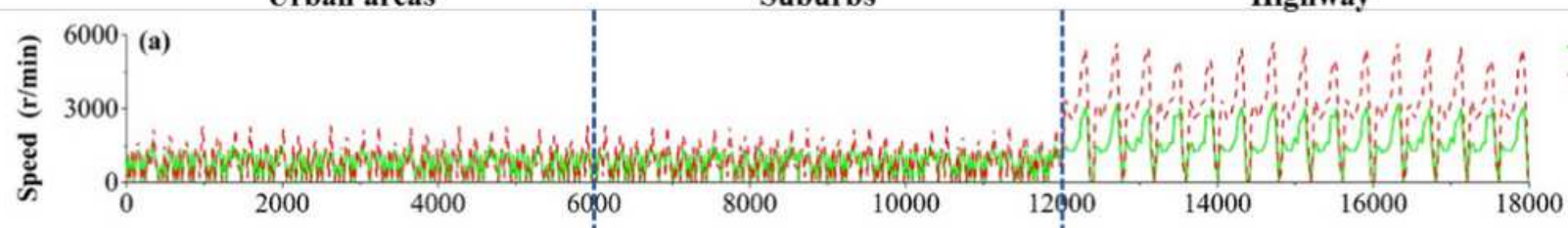

- Primary pulley speed

Secondary pulley speed

0.050 (b)
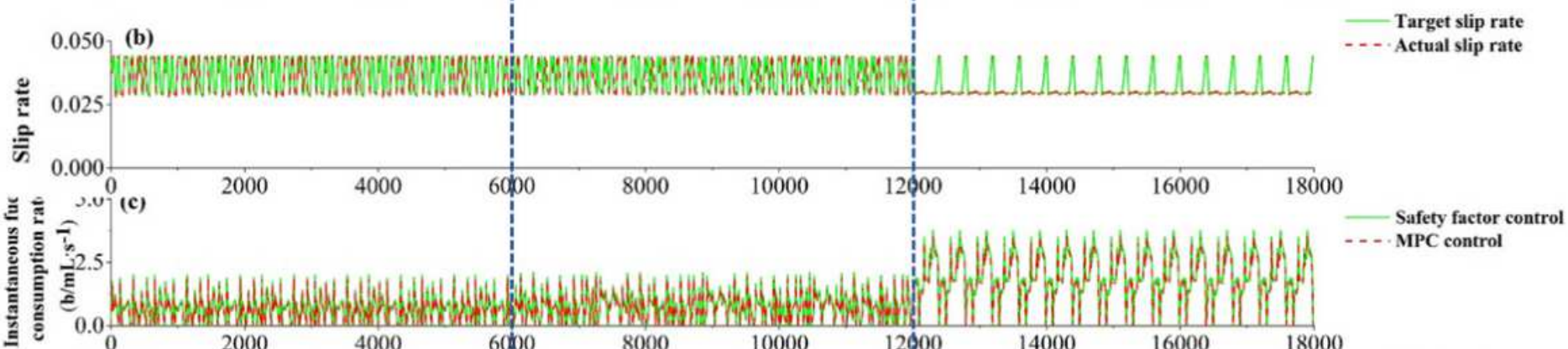

$\begin{array}{rrrrrrrr}2000 & 4000 & 6000 & 8000 & 10000 & 12600 & 14000 & 16000\end{array}$

\begin{tabular}{l|l|l}
3.0 & (d) & Target ratio
\end{tabular}

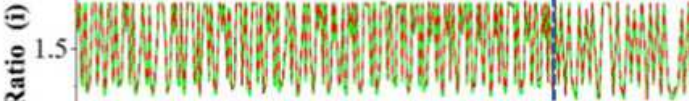

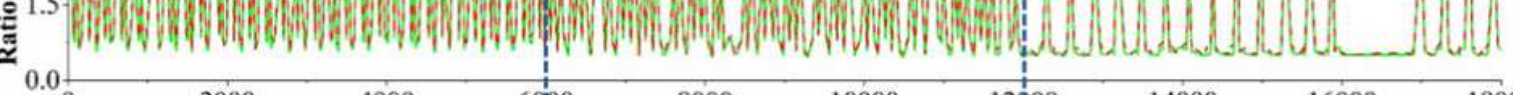

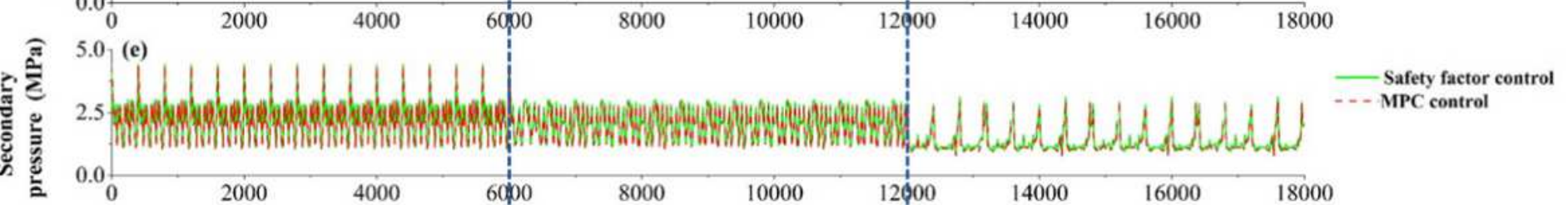

兽

1507 (f)

है

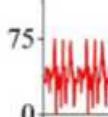

M.

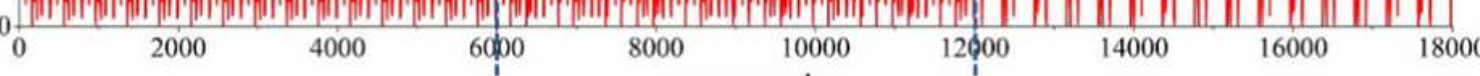

Time $\left(10^{-1} s\right)$

Figure 20

NEDC cycle conditions test (a) primary and secondary pulley speed (b) slip (c) instantaneous fuel consumption rate(d) ratio (e) secondary pulley pressure and (f) engine torque 


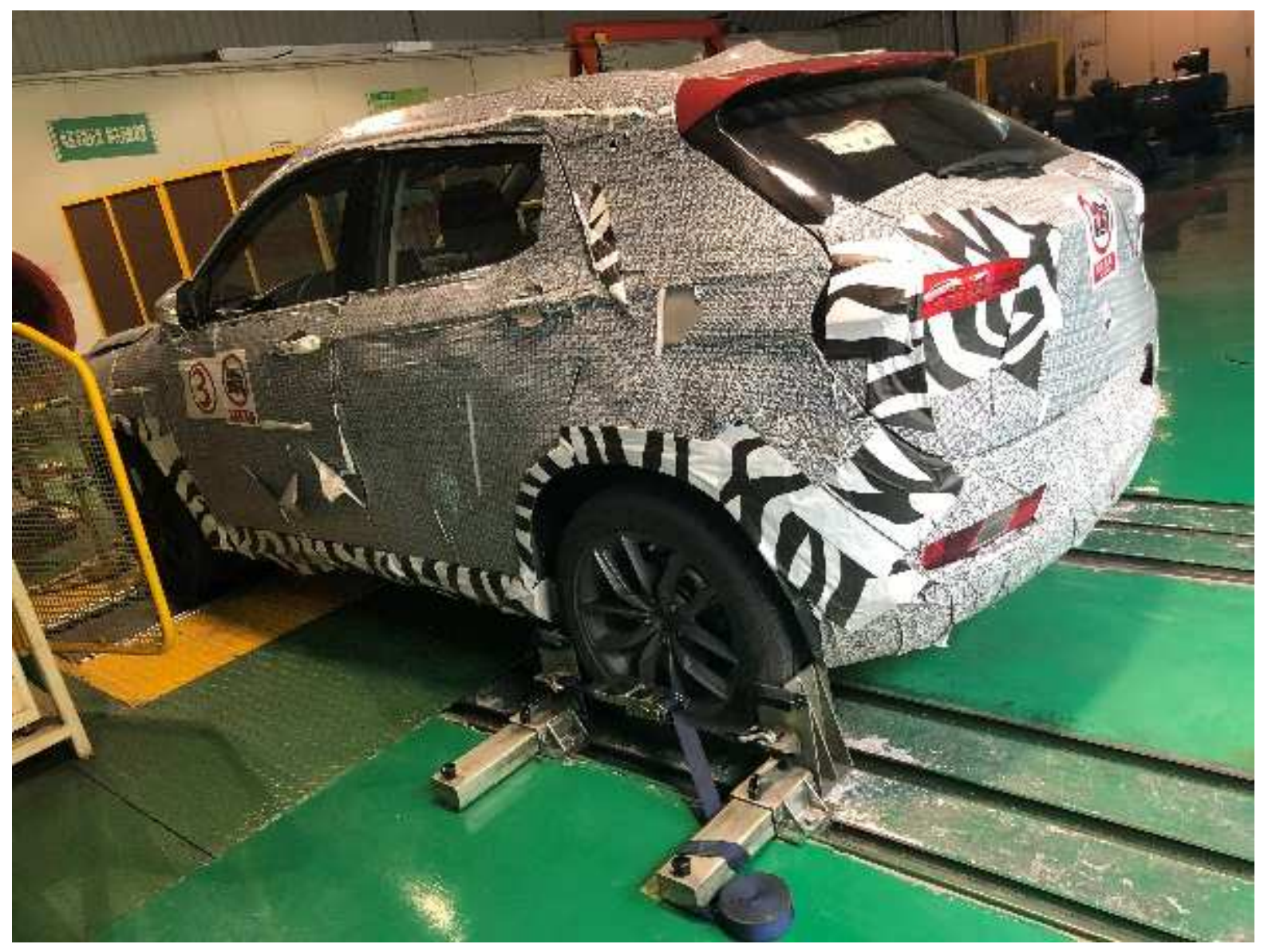

Figure 21

Real vehicle for drum test
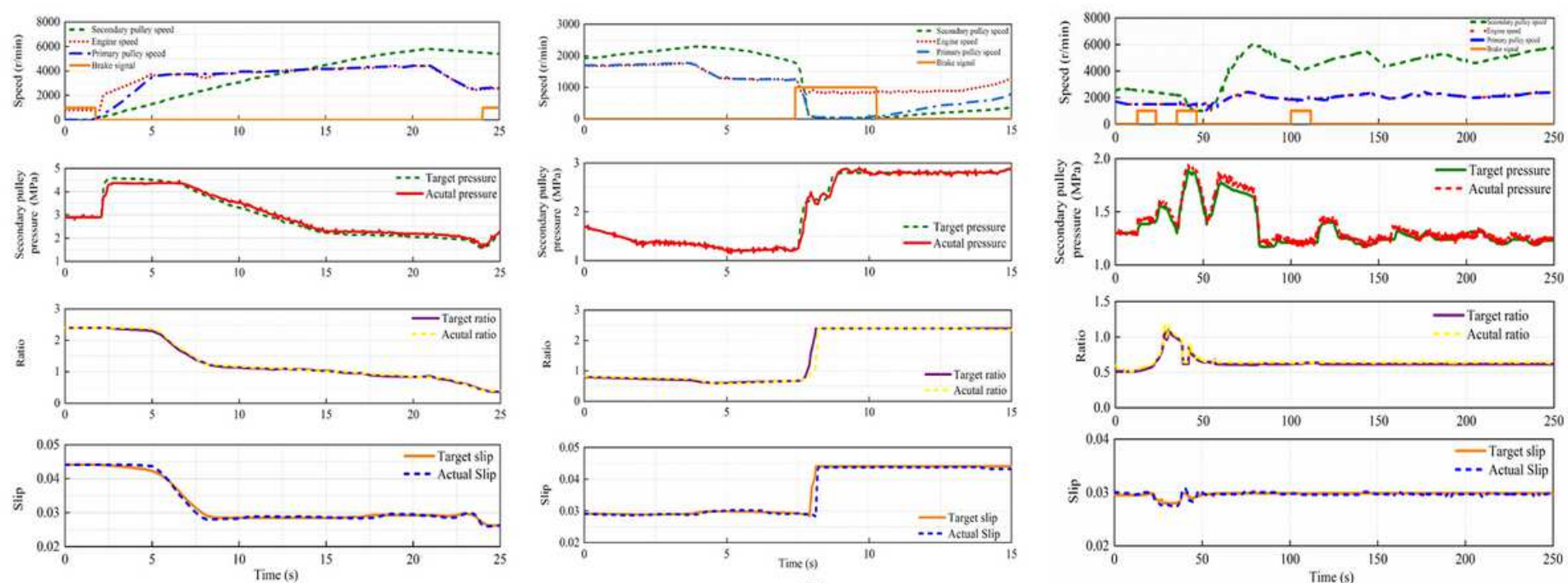

(a)

(b)
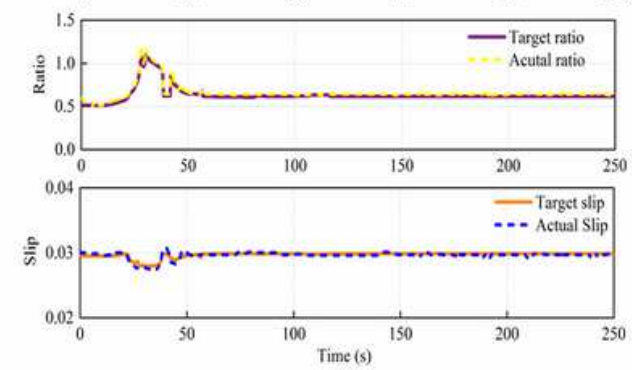

(c)

Figure 22

(a), (b) and (c) are working condition test of CVT vehicle for the accelerate, the rapid deceleration and the comprehensive conditions respectively 

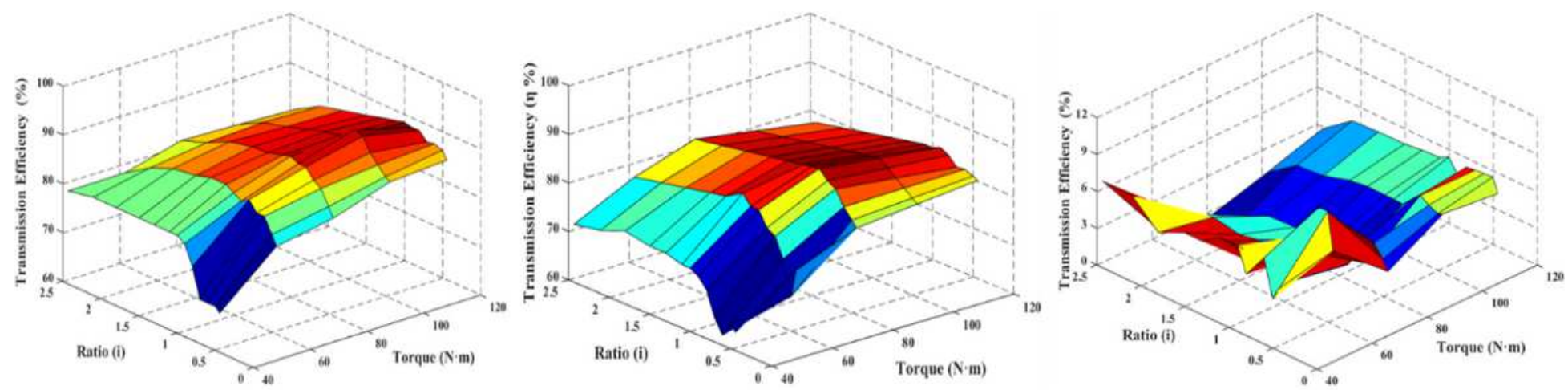

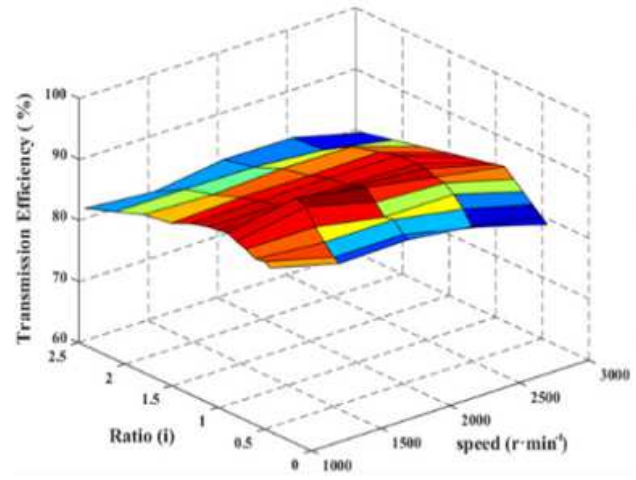

(a)

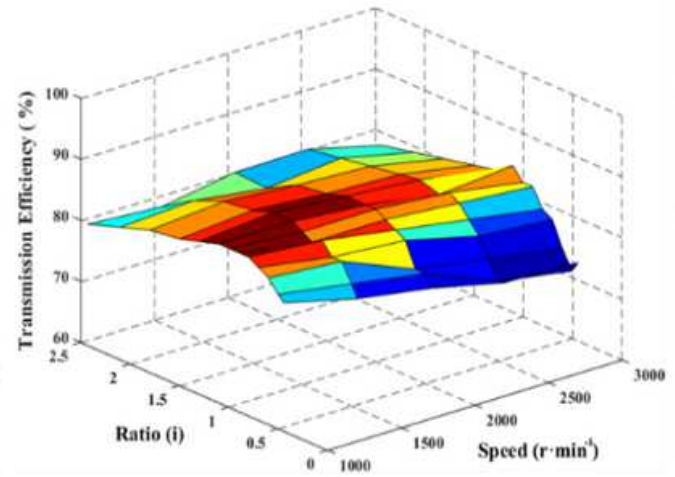

(b)

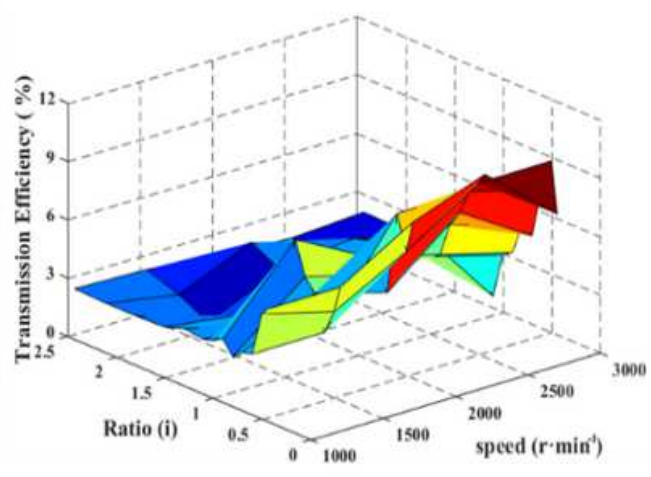

(c)

\section{Figure 23}

Comparison of efficiency improvement of CVT (a) Traditional control (b) MPC control (c) efficiency difference 